Research Article

\title{
Pseudo-Three-Dimensional Analysis for Functionally Graded Plate Integrated with a Piezoelectric Fiber Reinforced Composite Layer
}

\author{
Wei Wang, ${ }^{1,2}$ Sen Li $\mathbb{D}^{3},{ }^{3}$ Lin-Quan Yao $\mathbb{D}^{1},{ }^{1}$ and Shi-Chao $\mathrm{Yi}^{4}$ \\ ${ }^{1}$ School of Rail Transportation, Soochow University, Suzhou 215131, China \\ ${ }^{2}$ School of Mathematical Sciences, Soochow University, Suzhou 215006, China \\ ${ }^{3}$ School of Mathematical Sciences and Chemical Engineering, Changzhou Institute of Technology, Changzhou 213032, China \\ ${ }^{4}$ School of Science, Jiangsu University of Science and Technology, Zhenjiang 212003, China \\ Correspondence should be addressed to Lin-Quan Yao; lqyao@suda.edu.cn
}

Received 18 December 2018; Revised 22 February 2019; Accepted 7 March 2019; Published 24 April 2019

Academic Editor: Francesco Tornabene

Copyright (C) 2019 Wei Wang et al. This is an open access article distributed under the Creative Commons Attribution License, which permits unrestricted use, distribution, and reproduction in any medium, provided the original work is properly cited.

\begin{abstract}
In this paper, a pseudo-three-dimensional method is proposed to investigate static behavior analysis of functionally graded (FG) plate integrated with a piezoelectric fiber reinforced composite (PFRC) layer by the hyperbolic shear and normal deformation theory. The present method is a displacement-based theory which accounts for hyperbolic variation of in-plane displacement field and parabolic variation of transverse displacement field. The linear electrical potential function in the PFRC layer is modeled. The governing equations of present method are derived by the minimum potential energy principle and Navier's procedure is used to solve the equations. Numerical results are presented to demonstrate the efficiency of the proposed method. The effects of some parameters including material composition, aspect ratios, and applied voltages on the deformations of the plate are investigated. Compared with the available data of numerical method and 3D method, the presented method is more suitable for the smart FG structure.
\end{abstract}

\section{Introduction}

The functionally graded materials (FGMs) have become an important issue for advanced structural applications in many areas such as aerospace, automation, medicine, energy, and optoelectronic. Due to the important applications of the FGMs, many researchers affect improving material processing, fabrication processing, and studying the mechanics and mechanism of FGM structures. Various approaches of analytical, numerical, and experimental methods have been proposed to deal with the problems involving FGMs. Since the early 1990s, displacement-based theories had been used in the analysis of FG beam, plate, and shell structures. These theories were derived by making suitable assumptions concerning kinematics of deformation and stress state through the thickness direction, such as the classical plate theory (CLPT), the first-order shear deformation theory (FSDT) $[1,2]$, and the third-order shear deformation theory (TSDT) [3-5].
These assumptions allow the reduction of a $3 \mathrm{D}$ problem to a $2 \mathrm{D}$ problem and neglect normal deformation effects $\left(\varepsilon_{z}=0\right)$. The CLPT is based on the Kirchhoff hypothesis and neglects the effect of transverse shear strain, which applies to thin plates, but not to medium and thick plates. The FSDT considers the shear deformation effect on linear variation of in-plane displacements through the thickness direction; this assumption leads to a constant shear stress state; thus, a shear correction factor is required to compensate for the difference between the actual and assumed stress state. Usually, the factor is dependent on many parameters including geometry, boundary conditions, and loading conditions and it is hard to find out consistently. To overcome the drawbacks, Reddy proposed the third-order shear deformation plate theory which considered the shear deformation effects based on a higherorder variation of in-plane displacement fields through the thickness of the plate and the shear correction factor is not required. The theory including normal deformation effects 
$\left(\varepsilon_{z} \neq 0\right)$ can be firstly found in the literature by Kant and Manjunatha [6] using the finite element method, in which the cubic polynomial expansion were applied in both in-plane and transverse displacement fields. Some other methods considering the normal deformation effects have been proposed in the literatures [7-13]. The aforementioned theories can be called higher-order shear and normal deformation theory (HOSNT), which include higher-order variation transverse displacement field. Recently, the effect of thickness stretching has been investigated by Carrera et al. [14] using the finite element approximation. Neves et al. [10] presented bending and free vibration analysis of FG plates using radial basis function collocation method based on a hyperbolic shear deformation theory. Hebali and Thai $[15,16]$ developed quasi$3 \mathrm{D}$ solutions of bending and vibration analysis of FG plates using a hyperbolic shear deformation theory. Belabed et al. [17] obtained quasi-3D solutions for static and vibration analysis of the FG plate. Some other theories based on displacement assumptions can be found in the review article [18] in detail.

Three-dimensional exact solutions for FG plates are rather restricted in general and difficult to find unless some geometry and boundary conditions are relatively simple. Analytical 3D solutions for FG plates are very useful since they provided benchmark to assess the accuracy of various $2 \mathrm{D}$ theories, quasi-3D theories, and numerical methods. Fortunately, there are some studies about finding 3D exact solutions for FG plates. Cheng and Batra [19] presented 3D thermoelastic deformations of the FG elliptic plate. Reddy and Cheng [20] obtained 3D solutions of thermomechanical deformations of rectangular FG plates. An analytical solution of threedimensional thermomechanical deformations of a simply supported FG rectangular plate subjected to time-dependent thermal load was presented by Vel and Batra [21]. Anderson [22] analyzed 3D elasticity solutions for a sandwich composite plate with FGM core. Senthil [23] obtained 3D exact solutions for free and forced vibration of the FG plate and Kashtalyan [24] developed 3D elasticity solutions for the FG plate subjected to transverse loading. The bending analysis of an exponentially graded thick rectangular plate using both twodimensional trigonometric shear deformation and threedimensional elasticity theory was given by Zenkour [25].

In order to develop the structures with self-controlling and self-monitoring capabilities, piezoelectric material is an ideal material which can be used as distributed actuators and sensors. Piezoelectric material is such that when it is subjected to a mechanical load, it generates an electrical charge which is usually called direct piezoelectric effect. Conversely, mechanical stress or strain occurs when piezoelectric material is subjected to an applied voltage; this phenomenon is known as the converse piezoelectric effect. The essential feature of piezoelectric materials is the capability of energy transformation between electrical energy and mechanical energy. Hence, piezoelectric materials can be tailored for developing smart structures and have been widely used in various applications such as automotive sensors, actuators, ultrasonic transducers, microelectromechanical system (MEMS) technology, and active damping devices. The functionally graded plates integrated with piezoelectric materials have also been studied by many researchers. Ootao and Tanigawa [26] gave 3D theoretical analysis of functionally graded rectangular plates bonded to a piezoelectric plate subjected to transient thermal loading. Reddy and Cheng [27] obtained 3D solutions of FG plates with an attached piezoelectric active material. He et al. [28] presented the active control of piezoelectric FG plate using the finite element formulation based on the classical plate theory. The nonlinear vibration and dynamic response of FG plates bonded with a piezoelectric layer in thermal environments are developed by Huang and Sheng [29]. Kargarnovin et al. [30] gave the vibration analysis of a simply FG rectangular plate with piezoelectric patches on its top or bottom surface. Brischetto and Carrera [31] investigated the piezoelectric FG plate using a refined plate theory.

Although the piezoelectric materials have been widely used as intelligent control devices, due to the small stressstrain coefficients of the monolithic piezoelectric material, the control authority of monolithic piezoelectric material is very low. Mallik and Ray [32] proposed the concept of piezoelectric fiber reinforced composite (PFRC) and obtained the effective coefficients of piezoelectric fiber reinforced composite through micromechanical analysis. It has been found that, when the fiber volume fraction exceeds a critical fiber volume fraction, the effective piezoelectric coefficient becomes significantly larger than the corresponding coefficient of the piezoelectric material. Ray and Sachade [33] dealt with $3 \mathrm{D}$ exact solutions for the static analysis of the FG plate integrated with a PFRC layer subjected to an electromechanical loading. They subsequently studied the effects of the variation of the piezoelectric angle in the PFRC layer using the finite element model [34]. Shiyekar and Kant [35] used a higher-order shear and normal deformation theory to analyze the FG plate integrated with a piezoelectric reinforced composite layer.

In present work, a pseudo-three-dimensional method is presented to study a simply supported piezoelectric FG plate by the hyperbolic shear and normal deformation theory. The effects of some parameters including material composition, aspect ratios, and applied voltages on the deformations of the plate are investigated. The obtained results are compared with numerical solutions and $3 \mathrm{D}$ exact solutions to verify the accuracy and the efficiency of the present method.

\section{Mathematical Modeling and Formulation}

2.1. Geometrical Configuration. Consider a rectangular FG plate with total thickness $h$, length $a$, and width $b$ as shown in Figure 1. The top and bottom surfaces of the FG plate are at $z= \pm h / 2$ and the edges of the plate are parallel to $x$ and $y$ axes, respectively. The top surface of the FG plate is integrated with a piezoelectric fiber reinforced composite (PFRC) layer with thickness $h_{p}$, acting as a distributed actuator of the FG plate. In the FG plate, due to gradually changing of volume fraction, the material properties are assumed to obey an exponential function through the thickness direction. The effective Young's modulus E( $z$ ) was given by [25]

$$
E(z)=E_{0} e^{p(0.5+z / h)}, \quad z \in\left[\frac{-h}{2}, \frac{h}{2}\right],
$$




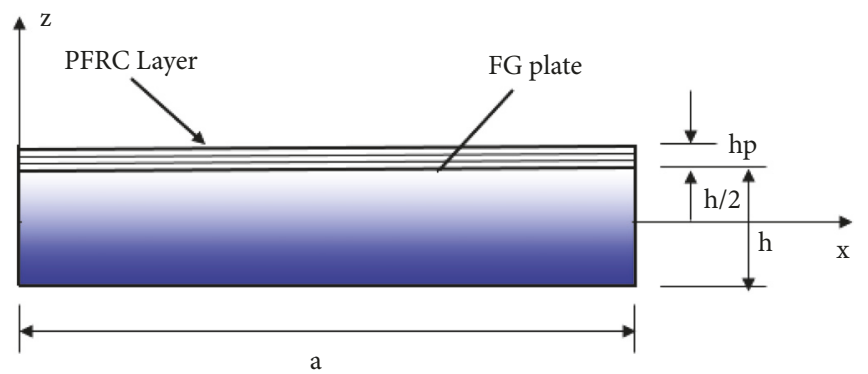

FIGURE 1: Geometry of the rectangular FG plate integrated with a PFRC layer.

which dictated the material property through the thickness of the FG plate with a gradient parameter $(0 \leq p \leq+\infty) p$. Young's modulus $E_{b}=E_{0}$ and $E_{t}=E_{0} e^{p}$ represent the material properties of the bottom surface and the top surface of the FG plate, respectively. Poisson's ratio of the FG plate was assumed to be constant for that the effect of Poisson's ratio on the deformation is much less than that of Young's modulus [36].

2.2. Displacement Field. The present higher-order shear and normal deformation theory have been given by Neves et al. [9, 10, 37-39]. They have given the bending, vibration, and buckling analysis of FG plates using meshless radial basis function collocation method based on polynomial, hyperbolic, and sinusoidal higher-order displacement field. Navier's solutions for a simply supported FG plate with a PFRC layer are not given for present higher-order shear and normal deformation theory which is given by

$$
\begin{aligned}
u(x, y, z, t)= & u_{0}(x, y, t)+z u_{1}(x, y, t) \\
& +f(z) u_{2}(x, y, t), \\
v(x, y, z, t)= & v_{0}(x, y, t)+z v_{1}(x, y, t) \\
& +f(z) v_{2}(x, y, t), \\
w(x, y, z, t)= & w_{0}(x, y, t)+z w_{1}(x, y, t) \\
& +z^{2} w_{2}(x, y, t),
\end{aligned}
$$

where $u, v$, and $w$ are displacement components in the $x, y$, and $z$ direction, respectively. The parameters $\left(u_{i}, v_{i}, w_{i}\right)(i=$ $0,1,2)$ are unknown functions to be determined. $f(z)$ is the shape function representing the distribution of transverse strain and shear stress through the thickness direction. The shape function can be polynomial function, hyperbolic function, or sinusoidal function. In this paper, a hyperbolic sinusoidal function is used for the bending analysis of the smart FG plate such that

$$
f(z)=\sinh \left(\frac{\pi z}{h}\right) .
$$

2.3. Strain-Displacement Relations and Constitutive Equations. The linear strain-displacement relationship for FG piezoelectric materials is given by

$$
\varepsilon_{x}=\frac{\partial u_{0}}{\partial x}+z \frac{\partial u_{1}}{\partial x}+f(z) \frac{\partial u_{2}}{\partial x}
$$

$$
\begin{aligned}
\varepsilon_{y}= & \frac{\partial v_{0}}{\partial y}+z \frac{\partial v_{1}}{\partial y}+f(z) \frac{\partial v_{2}}{\partial y} \\
\varepsilon_{z}= & w_{1}+2 z w_{2}, \\
\gamma_{x y}= & \left(\frac{\partial u_{0}}{\partial y}+\frac{\partial v_{0}}{\partial x}\right)+z\left(\frac{\partial u_{0}}{\partial y}+\frac{\partial v_{0}}{\partial x}\right) \\
& +f(z)\left(\frac{\partial u_{0}}{\partial y}+\frac{\partial v_{0}}{\partial x}\right), \\
\gamma_{y z}= & v_{1}+f^{\prime}(z) v_{2}+\frac{\partial w_{0}}{\partial y}+z \frac{\partial w_{1}}{\partial y}+z^{2} \frac{\partial w_{2}}{\partial y}, \\
\gamma_{x z}= & u_{1}+f^{\prime}(z) u_{2}+\frac{\partial w_{0}}{\partial x}+z \frac{\partial w_{1}}{\partial x}+z^{2} \frac{\partial w_{2}}{\partial x} .
\end{aligned}
$$

For piezoelectric materials, the constitutive equations can be expressed as

$$
\begin{aligned}
\boldsymbol{\sigma}^{k} & =\mathbf{C}^{k} \boldsymbol{\varepsilon}-e^{T} \mathbf{E}, \\
\mathbf{D} & =e \boldsymbol{\varepsilon}+\kappa \mathbf{E} .
\end{aligned}
$$

and, for elastic functionally graded material, the constitutive equations are

$$
\boldsymbol{\sigma}^{k}=\mathbf{C}^{k} \boldsymbol{\varepsilon}
$$

where $\boldsymbol{\sigma}, \boldsymbol{\varepsilon}, \mathbf{E}$, and $\boldsymbol{D}$ represent the stress vector, the strain vector, the electric field vector, and the electric displacement vector, respectively. $\mathbf{C}, e$, and $\kappa$ are the elastic stiffness matrix, the piezoelectric constants matrix, and the dielectric matrix, respectively. The superscript $k$ represents either the PFRC layer or the FG layer according to the location of the PFRC layer. For example, if the top surface of plate is integrated with the PFRC layer then the values of $k$ as 1 and 2 denote the FG plate and the PFRC layer, respectively, and vice versa.

The components of stress and strain vectors are given by

$$
\begin{aligned}
\boldsymbol{\sigma} & =\left[\begin{array}{llllll}
\sigma_{x} & \sigma_{y} & \sigma_{z} & \sigma_{y z} & \sigma_{x z} & \sigma_{x y}
\end{array}\right]^{T}, \\
\boldsymbol{\varepsilon} & =\left[\begin{array}{lllllll}
\varepsilon_{x} & \varepsilon_{y} & \varepsilon_{z} & \gamma_{y z} & \gamma_{x z} & \gamma_{x y}
\end{array}\right]^{T} .
\end{aligned}
$$

The electric field vector and the electric displacement vector are given by

$$
\mathbf{D}=\left[\begin{array}{lll}
D_{x} & D_{y} & D_{z}
\end{array}\right]^{T},
$$




$$
\boldsymbol{E}=\left[\begin{array}{lll}
E_{x} & E_{y} & E_{z}
\end{array}\right]^{T},
$$

where the electric field vector $\mathbf{E}$ related to electric potential $\phi$ is given by

$$
\begin{aligned}
& E_{x}=-\frac{\partial \phi(x, y, z)}{\partial x}, \\
& E_{y}=-\frac{\partial \phi(x, y, z)}{\partial y}, \\
& E_{z}=-\frac{\partial \phi(x, y, z)}{\partial z} .
\end{aligned}
$$

The elastic stiffness matrix, the piezoelectric matrix, and the dielectric matrix are given by

$$
\begin{aligned}
\mathbf{C} & =\left[\begin{array}{cccccc}
C_{11} & C_{12} & C_{13} & 0 & 0 & 0 \\
C_{12} & C_{22} & C_{23} & 0 & 0 & 0 \\
C_{13} & C_{23} & C_{33} & 0 & 0 & 0 \\
0 & 0 & 0 & C_{44} & 0 & 0 \\
0 & 0 & 0 & 0 & C_{55} & 0 \\
0 & 0 & 0 & 0 & 0 & C_{66}
\end{array}\right], \\
e & =\left[\begin{array}{cccccc}
0 & 0 & 0 & 0 & e_{15} & 0 \\
0 & 0 & 0 & e_{24} & 0 & 0 \\
e_{31} & e_{32} & e_{33} & 0 & 0 & 0
\end{array}\right], \\
\kappa & =\left[\begin{array}{ccc}
\kappa_{11} & 0 & 0 \\
0 & \kappa_{22} & 0 \\
0 & 0 & \kappa_{33}
\end{array}\right],
\end{aligned}
$$

where $C_{i j}$ are the elastic constants, for isotropic functionally graded material, defined by

$$
\begin{aligned}
& C_{11}=C_{22}=C_{33}=\frac{(1-v) E(z)}{(1-2 \nu)(1+\nu)} \\
& C_{12}=C_{13}=C_{23}=\frac{v E(z)}{(1-2 \nu)(1+\nu)} \\
& C_{44}=C_{55}=C_{66}=\frac{E(z)}{2(1+v)} .
\end{aligned}
$$

2.4. Strain Energy due to Governing Equations. The minimum potential energy principle is used herein to derive governing equations and the principle can be determined by a summation of the variation of strain energy and work done by external force as follows:

$$
\delta U+\delta V=0 .
$$

The variation of strain energy is given explicitly by

$\delta U$

$$
\begin{aligned}
& =\sum_{k=1}^{2} \int_{A} \int_{h_{k}}^{h_{k+1}}\left(\sigma_{x}^{k} \delta \varepsilon_{x}\right. \\
& +\sigma_{y}^{k} \delta \varepsilon_{y}+\sigma_{z}^{k} \delta \varepsilon+\sigma_{x y}^{k} \delta \gamma_{x y}+\sigma_{x z}^{k} \delta \gamma_{x z} \\
& \left.+\sigma_{y z}^{k} \delta \gamma_{y z}\right) d z d A
\end{aligned}
$$

$$
\begin{aligned}
& =\int_{A}\left[\left(N_{x} \frac{\partial \delta u_{0}}{\partial x}\right.\right. \\
& \left.+N_{x y} \frac{\partial \delta u_{0}}{\partial y}\right)+\left(N_{x y} \frac{\partial \delta v_{0}}{\partial x}+N_{y} \frac{\partial \delta v_{0}}{\partial y}\right)+\left(Q_{x z} \frac{\partial \delta w_{0}}{\partial x}\right. \\
& \left.+Q_{y z} \frac{\partial \delta w_{0}}{\partial y}\right)+\left(M_{x} \frac{\partial \delta u_{1}}{\partial x}+M_{x y} \frac{\partial \delta u_{1}}{\partial y}\right. \\
& \left.+Q_{x z} \delta u_{1}\right)+\left(M_{x y} \frac{\partial \delta v_{1}}{\partial x}+M_{y} \frac{\partial \delta v_{1}}{\partial y}+Q_{y z} \delta v_{1}\right)+\left(M_{x z} \frac{\partial \delta w_{1}}{\partial x}\right. \\
& \left.+M_{y z} \frac{\partial \delta w_{1}}{\partial y}+Q_{z} \delta w_{1}\right)+\left(P_{x} \frac{\partial \delta u_{2}}{\partial x}+P_{x y} \frac{\partial \delta u_{2}}{\partial y}\right. \\
& \left.+P_{x z} \delta u_{2}\right)+\left(P_{x y} \frac{\partial \delta v_{2}}{\partial x}+P_{y} \frac{\partial \delta v_{2}}{\partial y}+P_{y z} \delta v_{2}\right)+\left(R_{x z} \frac{\partial \delta w_{2}}{\partial x}\right. \\
& \left.\left.+R_{y z} \frac{\partial \delta w_{2}}{\partial y}+2 M_{z} \delta w_{2}\right)\right] d A
\end{aligned}
$$

where $N, M, P, Q$, and $R$ are the stress resultants defined by

$$
\begin{aligned}
& \left(N_{x}, N_{y}, N_{x y}\right)=\sum_{k=1}^{2} \int_{h_{k}}^{h_{k+1}}\left(\sigma_{x}^{k}, \sigma_{y}^{k}, \sigma_{x y}^{k}\right) d z, \\
& \left(M_{x}, M_{y}, M_{x y}, M_{x z}, M_{y z}, M_{z}\right) \\
& \quad=\sum_{k=1}^{2} \int_{h_{k}}^{h_{k+1}}\left(\sigma_{x}^{k}, \sigma_{y}^{k}, \sigma_{x y}^{k}, \sigma_{x z}^{k}, \sigma_{y z}^{k}, \sigma_{z}^{k}\right) z d z, \\
& \left(P_{x}, P_{y}, P_{x y}\right)=\sum_{k=1}^{2} \int_{h_{k}}^{h_{k+1}}\left(\sigma_{x}^{k}, \sigma_{y}^{k}, \sigma_{x y}^{k}\right) f(z) d z, \\
& \left(Q_{x z}, Q_{y z}, Q_{z}\right)=\sum_{k=1}^{2} \int_{h_{k}}^{h_{k+1}}\left(\sigma_{x z}^{k}, \sigma_{y z}^{k}, \sigma_{z}^{k}\right) d z, \\
& \left(P_{x z}, P_{y z}\right)=\sum_{k=1}^{2} \int_{h_{k}}^{h_{k+1}}\left(\sigma_{x z}^{k}, \sigma_{y z}^{k}\right) f^{\prime}(z) d z, \\
& \left(R_{x z}, R_{y z}\right)=\sum_{k=1}^{2} \int_{h_{k}}^{h_{k+1}}\left(\sigma_{x z}^{k}, \sigma_{y z}^{k}\right) z^{2} d z,
\end{aligned}
$$

and $h_{k}(i=1,2,3)$ are the thickness coordinates from the bottom to the top of the smart FG plate. For example, if the PFRC layer is attached on the top of the FG plate, $h_{1}, h_{2}, h_{3}$ are $-h / 2, h / 2, h / 2+h_{p}$, respectively. Conversely, $h_{1}, h_{2}, h_{3}$ are $-h / 2-h_{p},-h / 2, h / 2$, respectively.

The variation of potential energy of applied transverse load $q$ can be expressed as

$$
\delta V=-\int_{A} q \delta\left(w_{0}+z w_{1}+z^{2} w_{2}\right) d A .
$$

Substitute the expressions of $\delta U$ and $\delta V$ in (13) and (15) into (12); then integrate by parts and collect the coefficients of $\delta u_{i}, \delta v_{i}$, and $\delta w_{i}(i=0,1,2)$. The following governing equations of present theory can be obtained:

$$
\delta u_{0}: \frac{\partial N_{x}}{\partial x}+\frac{\partial N_{x y}}{\partial y}=0,
$$




$$
\begin{aligned}
\delta v_{0}: \frac{\partial N_{x y}}{\partial x}+\frac{\partial N_{y}}{\partial y} & =0, \\
\delta w_{0}: \frac{\partial Q_{x z}}{\partial x}+\frac{\partial Q_{y z}}{\partial y}+q & =0, \\
\delta u_{1}: \frac{\partial M_{x}}{\partial x}+\frac{\partial M_{x y}}{\partial y}-Q_{x z} & =0, \\
\delta v_{1}: \frac{\partial M_{x y}}{\partial x}+\frac{\partial M_{y}}{\partial y}-Q_{y z} & =0, \\
\delta w_{1}: \frac{\partial M_{x z}}{\partial x}+\frac{\partial M_{y z}}{\partial y}-Q_{z}+z q & =0 \\
\delta u_{2}: \frac{\partial P_{x}}{\partial x}+\frac{\partial P_{x y}}{\partial y}-P_{x z} & =0 \\
\delta v_{2}: \frac{\partial P_{x y}}{\partial x}+\frac{\partial P_{y}}{\partial y}-P_{y z} & =0 \\
\delta w_{2}: \frac{\partial R_{x z}}{\partial x}+\frac{\partial R_{y z}}{\partial y}-2 M_{z}+z^{2} q & =0 .
\end{aligned}
$$

\section{Results and Discussion}

3.1. Numerical Illustration. It is assumed that the surface of the PFRC layer being in contact with the FG plate is suitably grounded. Since the thickness of the PFRC layer is very small, the electric potential can be considered as linear variation through the thickness of the PFRC layer. The electric potential function can be expressed as either

$$
\begin{aligned}
& \phi(x, y, z)=\frac{1}{h_{p}}\left(z-\frac{h}{2}\right) \phi_{0}(x, y), \\
& \frac{h}{2} \leq z \leq \frac{h}{2}+h_{p}, \\
& \operatorname{or} \phi(x, y, z)=-\frac{1}{h_{p}}\left(z+\frac{h}{2}\right) \phi_{0}(x, y), \\
&-\left(\frac{h}{2}+h_{p}\right) \leq z \leq \frac{-h}{2},
\end{aligned}
$$

according to the top surface or the bottom surface of the FG plate attached with the PFRC layer [34]. $\phi_{0}(x, y)$ is a generalized electric potential function at any point in the PFRC layer.

Substituting (2)-(6) and (17a)-(17b) into (14a)-(14f), the stress resultants can be eventually expressed in terms of generalized displacements $\left(u_{i}, v_{i}, w_{i}\right)(i=0,1,2)$ and electric potential $\phi_{0}$. The stress resultants and the corresponding coefficients are defined as relations in Appendix A. The FG plate attached to a piezoelectric layer either on the top or on the bottom is taken here. The sinusoidal mechanical loading and electric potential are applied to the smart FG plate. The mechanical load $q_{0}=-40 \mathrm{~N} / \mathrm{m}^{2}$ is applied on the top surface of the smart FG plate. For convenience, the following nondimensional parameters are used for presenting the numerical results:

$$
\begin{aligned}
u^{*} & =\frac{E_{0} u}{\left|q_{0}\right| s^{3} h}, \\
w^{*} & =\frac{100 E_{0} w}{\left|q_{0}\right| s^{4} h}, \\
\left(\sigma_{x}^{*}, \sigma_{y}^{*}, \sigma_{x y}^{*}\right) & =\frac{\left(\sigma_{x}, \sigma_{y}, \sigma_{x y}\right)}{\left|q_{0}\right| s^{2}} \\
\left(\sigma_{x z}^{*}, \sigma_{y z}^{*}\right) & =\frac{\left(\sigma_{x z}, \sigma_{y z}\right)}{\left|q_{0}\right| s}, \\
\sigma_{z}^{*} & =\frac{\sigma_{z}}{\left|q_{0}\right|}, \\
s & =\frac{a}{h} .
\end{aligned}
$$

3.2. Boundary Conditions. The following boundary conditions of present theory for simply supported FG plates are imposed:

$$
\begin{array}{r}
v_{0}=w_{0}=v_{1}=w_{1}=v_{2}=w_{2}=N_{x}=M_{x}=P_{x}=0 \\
\text { at } x=0, a, \\
u_{0}=w_{0}=u_{1}=w_{1}=u_{2}=w_{2}=N_{y}=M_{y}=P_{y}=0 \\
\text { at } y=0, b .
\end{array}
$$

Based on Navier's procedure, the following displacement components $\left(u_{i}, v_{i}, w_{i}\right)$ are assumed:

$$
\begin{aligned}
& u_{i}(x, y, t)=\sum_{m=1}^{\infty} \sum_{n=1}^{\infty} U_{i m n} \cos (\alpha x) \sin (\beta y), \\
& v_{i}(x, y, t)=\sum_{m=1}^{\infty} \sum_{n=1}^{\infty} V_{i m n} \sin (\alpha x) \cos (\beta y), \\
& w_{i}(x, y, t)=\sum_{m=1}^{\infty} \sum_{n=1}^{\infty} W_{i m n} \sin (\alpha x) \sin (\beta y),
\end{aligned}
$$

where $\alpha=m \pi / a, \beta=n \pi / b$, and $U_{i m n}, V_{i m n}, W_{i m n}(i=0,1,2)$ are unknown coefficients to be determined.

The transverse load $q$ and electric potential $\phi_{0}$ are also expanded in double-Fourier series as

$$
\begin{aligned}
q(x, y) & =\sum_{m=1}^{\infty} \sum_{n=1}^{\infty} q_{m n} \sin (\alpha x) \sin (\beta y), \\
\phi_{0}(x, y) & =\sum_{m=1}^{\infty} \sum_{n=1}^{\infty} \phi_{0 m n} \sin (\alpha x) \sin (\beta y) .
\end{aligned}
$$

Substituting (20) and (21) into (16a)-(16i), we can obtain the algebraic equations:

$$
\mathrm{KU}=\mathbf{f},
$$


where

$$
\begin{gathered}
\mathbf{U}=\left[U_{0 m n}, V_{0 m n}, W_{0 m n}, U_{1 m n}, V_{1 m n}, W_{1 m n}, U_{2 m n}, V_{2 m n},\right. \\
\left.W_{2 m n}\right]^{T} .
\end{gathered}
$$

and the symmetric matrix $\mathbf{K}$ and vector $\mathbf{f}$ are given in Appendix B.

3.3. Mechanical Properties. In this section, a simply supported rectangular FG plate attached with a PFRC layer under transverse load $q$ is taken into consideration. The thickness of the FG plate is considered as $3 \mathrm{~mm}$ and the PFRC layer is taken as $250 \mathrm{um}$. The following material properties of the bottom surface of the FG plate are given by

$$
\begin{aligned}
E_{0} & =200 G P a, \\
\nu & =0.3 .
\end{aligned}
$$

The piezoelectric fiber and matrix of the PFRC material are made of PZT5H and epoxy, respectively. Considering $40 \%$ fiber volume fraction, the following elastic and piezoelectric constants of the PFRC layer are obtained by using micromechanics models [33]:

$$
\begin{aligned}
& C_{11}=32.6 \mathrm{GPa}, \\
& C_{12}=4.3 \mathrm{GPa}, \\
& C_{13}=4.76 \mathrm{GPa}, \\
& C_{22}=C_{33}=7.2 \mathrm{GPa}, \\
& C_{23}=3.85 \mathrm{GPa}, \\
& C_{44}=1.05 \mathrm{GPa}, \\
& C_{55}=C_{66}=1.29 \mathrm{GPa}, \\
& e_{31}=-6.76 \mathrm{C} / \mathrm{m}^{2}, \\
& \kappa_{11}=\kappa_{22}=0.037 \times 10^{-9} \mathrm{C} / \mathrm{Vm}, \\
& \kappa_{33}=10.64 \times 10^{-9} \mathrm{C} / \mathrm{Vm} .
\end{aligned}
$$

The other coefficients $e_{32}, e_{33}, e_{15}$, and $e_{24}$ of the PFRC layer are smaller compared to the effective piezoelectric constant $e_{31}$ and therefore the piezoelectric coefficients $e_{32}$, $e_{33}, e_{15}$, and $e_{24}$ are not considered for deriving the system equations.

3.4. Numerical Validation. Numerical results of the displacement $u^{*}, w^{*}$ and the stress $\sigma_{x}^{*}, \sigma_{y}^{*}, \sigma_{x y}^{*}$ are presented in Tables $1-4$. The results for different aspect ratios $(s=10,20,100)$, applied voltages $(V=0,100,-100)$, and different values of the functionally graded material parameter are obtained. The results are compared with those provided by $3 \mathrm{D}$ theory [33], the finite element method [34], and the higher-order shear and normal deformation theory (HOSNT) [35]. In the HOSNT, the cubic polynomial expansion is applied in both in-plane and transverse displacement fields and it contains
12 unknown parameters. The finite element method analyzed the smart FG plate using eight node isoparametric quadrilateral element based on the first-order shear deformation theory. For the present method, it only has 9 unknowns to be determined and it is very efficient in predicting bending analysis of the smart FG plate for different aspect ratios and applied electric voltages. The aforementioned methods are derived by making displacement assumptions concerning the kinematics of deformations or the stress state through the thickness of the plate.

Tables 1 and 2 show the results of the FG plate attached with the PFRC layer on the top surface for $E_{t} / E_{b}=10$ and 0.1 , respectively. The results of the FG plate attached with the PFRC layer on the bottom surface are presented in Tables 3 and 4, respectively. It can be observed that the results developed by the present method; the HOSNT and the FEM are very close to each other and the results are in good accordance with $3 \mathrm{D}$ exact solutions. These results demonstrate that when the PFRC layer is subjected to a positive voltage, it counteracts the deformation caused by the vertically applied downward mechanical load. Conversely, while for applying a negative voltage, the PFRC layer increases the deformation, the deformations are also significantly influenced by the sign of applied voltages and therefore the PFRC layer can be acting as a distributed actuator for functionally graded plates. Moreover, the deformations of the FG plates with $E t / E_{b}=0.1$ are much larger than the FG plates with $E t / E_{b}=10$.

In order to illustrate the accuracy of present method, the transverse stresses $\sigma_{x z}^{*}, \sigma_{y z}^{*}, \sigma_{z}^{*}$ obtained by present method and $3 \mathrm{D}$ theory [33] are presented in Tables 5 and 6 . The results are computed for FG plates attached to the PFRC layer on the top surface with $E t / E_{b}=10$ and 0.1 , respectively. It can be seen that the present results for both thick and thin FG plates are in good agreement with $3 \mathrm{D}$ exact solutions.

In Figures 2(a) and 2(b), the variation of the in-plane displacement $u^{*}$ and the transverse displacement $w^{*}$ through the thickness of thin FG plates $(s=100)$ attached to the PFRC layer on the top surface is shown. The in-plane displacement $u^{*}$ is linear variation, while the transverse displacement is kept at a constant. The in-plane stresses $\sigma_{x}^{*}, \sigma_{y}^{*}, \sigma_{x y}^{*}$ and the transverse stresses $\sigma_{x z}^{*}, \sigma_{y z}^{*}, \sigma_{z}^{*}$ are plotted in Figures 3 and 4 , respectively. All the stress results are nonlinear variation through the thickness of the FG plate. The stress results change in the opposite trend when the PFRC layer is subjected to different signs of applied voltages. The effects of the sign of the applied voltage on numerical results are illustrated again from these figures. Because of the nonzero piezoelectric constant $e_{31}$, the variation of the normal stress $\sigma_{x}^{*}$ near the top surface is more than the normal stress $\sigma_{y}^{*}$ in the FG plate.

\section{Conclusions}

This paper presented a pseudo-three-dimensional method to analyze a simply supported FG plate attached to a piezoelectric reinforced composite layer by the higher-order shear and normal deformation theory. The piezoelectric fibers in the PFRC layer are oriented longitudinally along the length 
TABLE 1: Results of the FG plate $\left(E_{t} / E_{b}=10\right)$ attached to the PFRC layer on the top surface with and without applied voltage.

\begin{tabular}{|c|c|c|c|c|c|c|c|c|c|c|}
\hline \multicolumn{2}{|c|}{ Aspect ratio } & \multicolumn{3}{|c|}{$\mathrm{s}=10$} & \multicolumn{3}{|c|}{$s=20$} & \multicolumn{3}{|c|}{$\mathrm{s}=100$} \\
\hline Quantity & Theory & $\mathrm{V}=0$ & $\mathrm{~V}=100$ & $V=-100$ & $\mathrm{~V}=0$ & $\mathrm{~V}=100$ & $\mathrm{~V}=-100$ & $\mathrm{~V}=0$ & $V=100$ & $V=-100$ \\
\hline \multirow[t]{4}{*}{$w^{*}$} & HOSNT [35] & -0.9575 & 187.8140 & -189.7290 & -0.9251 & 45.5336 & -47.3839 & -0.9147 & 0.9342 & -2.7635 \\
\hline & $3 \mathrm{D}[33]$ & -0.9553 & 186.8222 & -188.7329 & -0.9252 & 45.5393 & -47.3897 & -0.9155 & 0.9368 & -2.7678 \\
\hline & FEM [34] & -0.9485 & 183.9178 & -185.8148 & -0.9233 & 45.2938 & -47.1403 & -0.9145 & 0.9328 & -2.7619 \\
\hline & Present & -0.9544 & 187.6270 & -189.5358 & -0.9249 & 45.5708 & -47.4207 & -0.9155 & 0.9360 & -2.7669 \\
\hline \multirow[t]{8}{*}{$u^{*}$} & HOSNT [35] & -0.0194 & -0.0233 & -0.0156 & -0.0195 & -0.0340 & -0.0049 & -0.0195 & -0.0202 & -0.0187 \\
\hline & & 0.0093 & -5.9832 & 6.0018 & 0.0093 & -1.4685 & 1.4870 & 0.0092 & -0.0496 & 0.0681 \\
\hline & $3 \mathrm{D}[33]$ & -0.0194 & -0.0307 & -0.0081 & -0.0195 & -0.0337 & -0.0053 & -0.0195 & -0.0202 & -0.0188 \\
\hline & & 0.0093 & -5.9373 & 5.9558 & 0.0093 & -1.4670 & 1.4855 & 0.0093 & -0.0497 & 0.0682 \\
\hline & FEM [34] & -0.0195 & 0.0459 & -0.0849 & -0.0195 & -0.0297 & -0.0093 & -0.0195 & -0.0202 & -0.0187 \\
\hline & & 0.0093 & -5.9402 & 5.9588 & 0.0093 & -1.4655 & 1.4840 & 0.0093 & -0.0496 & 0.0681 \\
\hline & Present & -0.0196 & 0.0672 & -0.1063 & -0.0195 & -0.0276 & -0.0114 & -0.0195 & -0.0202 & -0.0188 \\
\hline & & 0.0092 & -5.9753 & 5.9938 & 0.0093 & -1.4688 & 1.4874 & 0.0093 & -0.0496 & 0.0682 \\
\hline \multirow[t]{8}{*}{$\sigma_{x}^{*}$} & HOSNT [35] & 0.0873 & -5.9143 & 6.0891 & 0.0873 & -1.3682 & 1.5427 & 0.0872 & 0.0296 & 0.1448 \\
\hline & & -0.4247 & 206.3480 & -207.1980 & -0.4191 & 50.5808 & -51.4189 & -0.4172 & 1.6138 & -2.4483 \\
\hline & $3 \mathrm{D}[33]$ & 0.0871 & -5.8052 & 5.9794 & 0.0873 & -1.3742 & 1.5489 & 0.0874 & 0.0291 & 0.1457 \\
\hline & & -0.4201 & 203.9840 & -204.8249 & -0.4171 & 50.3911 & -51.2253 & -0.4161 & 1.6124 & -2.4446 \\
\hline & FEM [34] & 0.0893 & -6.1985 & 6.3772 & 0.0893 & -1.4170 & 1.5427 & 0.0893 & 0.0299 & 0.1486 \\
\hline & & -0.4250 & 208.1964 & -209.0447 & -0.4250 & 51.4183 & -51.4189 & -0.4247 & 1.6447 & -2.4941 \\
\hline & Present & 0.0881 & -6.2363 & 6.4124 & 0.0876 & -1.3995 & 1.5747 & 0.0874 & 0.0291 & 0.1457 \\
\hline & & -0.4252 & 206.0779 & -206.9283 & -0.4182 & 50.4945 & -51.3309 & -0.4160 & 1.6113 & -2.4434 \\
\hline \multirow[t]{8}{*}{$\overline{\sigma_{y}^{*}}$} & HOSNT [35] & 0.0873 & -19.8310 & 20.0051 & 0.0872 & -4.9293 & 5.1036 & 0.0871 & -0.1140 & 0.2882 \\
\hline & & -0.4256 & 59.2543 & -60.1056 & -0.4199 & 14.4701 & -15.3100 & -0.4181 & 0.1771 & -1.0134 \\
\hline & $3 \mathrm{D}[33]$ & 0.0870 & -19.6720 & 19.8460 & 0.0872 & -4.9333 & 5.1078 & 0.0873 & -0.1145 & 0.2892 \\
\hline & & -0.4213 & 57.9752 & -58.8187 & -0.4180 & 14.3338 & -15.1698 & -0.4170 & 0.1751 & -1.0090 \\
\hline & FEM [34] & 0.0893 & -20.1638 & 20.3424 & 0.0893 & -5.0400 & 5.2185 & 0.0892 & -0.1167 & 0.2951 \\
\hline & & -0.4260 & 58.2432 & -59.0951 & -0.4259 & 14.5560 & -15.4079 & -0.4256 & 0.1772 & -1.0283 \\
\hline & Present & 0.0880 & -19.9654 & 20.1414 & 0.0875 & -4.9489 & 5.1239 & 0.0873 & -0.1144 & 0.2891 \\
\hline & & -0.4261 & 59.1653 & -60.0174 & -0.4191 & 14.3937 & -15.2319 & -0.4169 & 0.1746 & -1.0083 \\
\hline \multirow[t]{8}{*}{$\sigma_{x y}^{*}$} & HOSNT [35] & -0.0469 & 6.9021 & -6.9960 & -0.0470 & 1.6983 & -1.7923 & -0.0470 & 0.0229 & -0.1169 \\
\hline & & 0.2251 & -71.0439 & 71.4941 & 0.2242 & -17.4332 & 17.8816 & 0.2239 & -0.4803 & 0.9281 \\
\hline & $3 \mathrm{D}[33]$ & -0.0469 & 6.8593 & -6.9530 & -0.0470 & 1.6982 & -1.7922 & -0.0470 & 0.0230 & -0.1171 \\
\hline & & 0.2242 & -70.4771 & 70.9256 & 0.2243 & -17.4232 & 17.8717 & 0.2243 & -0.4813 & 0.9298 \\
\hline & FEM [34] & -0.0481 & 7.1027 & -7.1989 & -0.0481 & 1.7394 & -1.8356 & 0.0480 & 0.0233 & -0.1194 \\
\hline & & 0.2290 & -71.7882 & 72.7882 & 0.2290 & -17.7746 & 18.2326 & 0.2289 & -0.4907 & 0.9486 \\
\hline & Present & -0.0472 & 7.0270 & -7.1215 & -0.0471 & 1.7079 & -1.8021 & -0.0470 & 0.0230 & -0.1171 \\
\hline & & 0.2239 & -70.9436 & 71.3913 & 0.2242 & -17.4457 & 17.8940 & 0.2242 & -0.4810 & 0.9295 \\
\hline
\end{tabular}

(i) $w^{*}=w^{*}(a / 2, b / 2,0), u^{*}=u^{*}(0, b / 2, \mp h / 2),\left(\sigma_{x}^{*}, \sigma_{y}^{*}\right)=\left(\sigma_{x}^{*}, \sigma_{y}^{*}\right)(a / 2, b / 2, \mp h / 2)$, and $\sigma_{x y}^{*}=\sigma_{x y}^{*}(0,0, \mp h / 2)$.

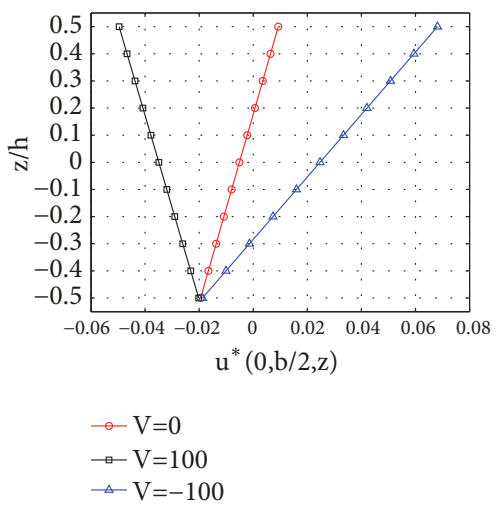

(a)

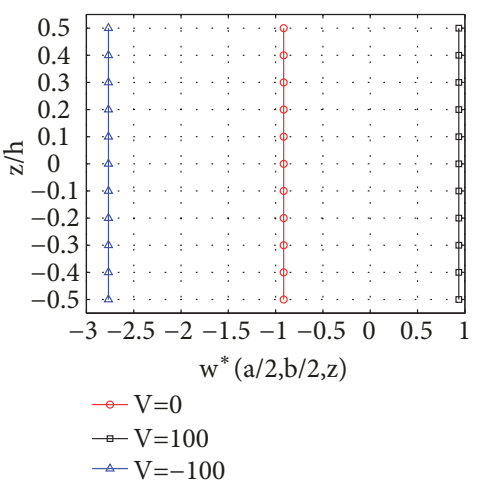

(b)

FIGURE 2: The variation of displacement results through the thickness of the FG plate $\left(E_{t} / E_{b}=10, s=100\right)$ attached with the PFRC layer on the top surface with or without applied voltage. (a) The in-plane displacement $u^{*}$. (b) The transverse displacement $w^{*}$. 
TABle 2: Results of the FG plate $\left(E_{t} / E_{\mathrm{b}}=0.1\right)$ attached to the PFRC layer on the top surface with and without applied voltage.

\begin{tabular}{|c|c|c|c|c|c|c|c|c|c|c|}
\hline \multicolumn{2}{|c|}{ Aspect ratio } & \multicolumn{3}{|c|}{$s=10$} & \multicolumn{3}{|c|}{$\mathrm{s}=20$} & \multicolumn{3}{|c|}{$\mathrm{s}=100$} \\
\hline Quantity & Theory & $V=0$ & $\mathrm{~V}=100$ & $V=-100$ & $\mathrm{~V}=0$ & $\mathrm{~V}=100$ & $V=-100$ & $V=0$ & $\mathrm{~V}=100$ & $V=-100$ \\
\hline \multirow[t]{4}{*}{$w^{*}$} & HOSNT [35] & -8.6140 & 3164.12 & -3181.35 & -8.3577 & 790.3310 & -807.0460 & -8.2750 & 23.7481 & -40.2981 \\
\hline & $3 \mathrm{D}[33]$ & -8.7397 & 3253.30 & -3270.80 & -8.5437 & 813.7105 & -830.7979 & -8.4806 & 23.9160 & -40.5745 \\
\hline & FEM [34] & -8.6673 & 3212.90 & -3230.30 & -8.4154 & 797.9455 & -814.7764 & -8.3292 & 24.4974 & -41.4587 \\
\hline & Present & -8.7085 & 3299.60 & -3317.01 & -8.5275 & 815.3451 & -832.4000 & -8.4698 & 24.4438 & -41.3835 \\
\hline \multirow[t]{8}{*}{$u^{*}$} & HOSNT [35] & -0.0905 & -3.8486 & 3.6674 & -0.0899 & -1.1482 & 0.9883 & -0.0897 & -0.1336 & -0.0458 \\
\hline & & 0.1653 & -112.9800 & 113.3110 & 0.1689 & -26.5921 & 26.9299 & 0.1701 & -0.8807 & 1.2209 \\
\hline & $3 \mathrm{D}[33]$ & -0.0914 & -3.1845 & 3.0017 & -0.0912 & -0.9839 & 0.8015 & -0.0912 & -0.1285 & -0.0539 \\
\hline & & 0.1686 & -114.0117 & 114.3489 & 0.1735 & -27.0971 & 27.4441 & 0.1750 & -0.8991 & 1.2493 \\
\hline & FEM [34] & -0.0901 & -3.0418 & 2.8616 & -0.0902 & -1.0641 & 0.8838 & -0.0901 & -0.1322 & -0.0480 \\
\hline & & 0.1714 & -107.7880 & 108.1308 & 0.1716 & -26.3653 & 26.7085 & 0.1715 & -0.8840 & 1.2270 \\
\hline & Present & -0.0910 & -2.3375 & 2.1555 & -0.0911 & -0.9344 & 0.7522 & -0.0911 & -0.1285 & -0.0537 \\
\hline & & 0.1703 & -109.6641 & 110.0046 & 0.1737 & -26.7836 & 27.1311 & 0.1748 & -0.8969 & 1.2466 \\
\hline \multirow[t]{8}{*}{$\sigma_{x}^{*}$} & HOSNT [35] & 0.3908 & -33.7320 & 34.5138 & 0.3848 & -7.7446 & 8.5744 & 0.3829 & 0.0628 & 0.7031 \\
\hline & & -0.0848 & 47.3070 & -47.4767 & -0.0846 & 11.2600 & -11.4293 & -0.0845 & 0.3627 & -0.5319 \\
\hline & $3 \mathrm{D}[33]$ & 0.4042 & -41.0915 & 41.8999 & 0.4031 & -9.8557 & 10.6619 & 0.4027 & -0.0061 & 0.8115 \\
\hline & & -0.0807 & 44.3075 & -44.4689 & -0.0796 & 10.6491 & -10.8083 & -0.0793 & 0.3451 & -0.5036 \\
\hline & FEM [34] & 0.4066 & -42.1225 & 42.9357 & 0.4068 & -9.6579 & 10.4715 & 0.4066 & 0.0199 & 0.8013 \\
\hline & & -0.0793 & 43.0275 & -43.1862 & -0.0794 & 10.5905 & -10.7493 & -0.0793 & 0.3460 & -0.5046 \\
\hline & Present & 0.4083 & -44.3395 & 45.1561 & 0.4027 & -9.8812 & 10.6866 & 0.4009 & 0.0013 & 0.8006 \\
\hline & & -0.0804 & 42.7266 & -42.8874 & -0.0791 & 10.4844 & -10.6425 & -0.0786 & 0.3421 & -0.4994 \\
\hline \multirow[t]{8}{*}{$\sigma_{y}^{*}$} & HOSNT [35] & 0.3763 & -163.0770 & 163.8300 & 0.3697 & -41.0169 & 41.7565 & 0.3676 & -1.2950 & 2.0302 \\
\hline & & -0.0866 & 30.8163 & -30.9899 & -0.0862 & 7.7083 & -7.8808 & -0.0861 & 0.2267 & -0.3989 \\
\hline & $3 \mathrm{D}[33]$ & 0.3900 & -170.3199 & 171.0999 & 0.3883 & -43.1562 & 43.9327 & 0.3877 & -1.3654 & 2.1408 \\
\hline & & -0.0825 & 28.1032 & -28.2681 & -0.0812 & 7.1105 & -7.2729 & -0.0808 & 0.2088 & -0.3704 \\
\hline & FEM [34] & 0.3916 & -172.9020 & 173.6851 & 0.3913 & -43.5671 & 44.3496 & 0.3909 & -1.3748 & 2.1565 \\
\hline & & -0.0810 & 28.0609 & -28.2229 & -0.0810 & 7.0834 & -7.2453 & -0.0809 & 0.2072 & -0.3689 \\
\hline & Present & 0.3940 & -172.3681 & 173.1561 & 0.3877 & -43.0789 & 43.8543 & 0.3857 & -1.3566 & 2.1280 \\
\hline & & -0.0820 & 28.0188 & -28.1828 & -0.0806 & 7.0440 & -7.2052 & -0.0802 & 0.2061 & -0.3664 \\
\hline \multirow[t]{8}{*}{$\overline{\sigma_{x y}^{*}}$} & HOSNT [35] & -0.2116 & 55.3721 & -55.7955 & -0.2098 & 13.8615 & -14.2811 & -0.2091 & 0.3560 & -0.7743 \\
\hline & & 0.0408 & -19.0577 & 19.1394 & 0.0416 & -4.6504 & 4.7336 & 0.0418 & -0.1448 & 0.2285 \\
\hline & $3 \mathrm{D}[33]$ & -0.2138 & 56.9184 & -57.3461 & -0.2131 & 14.2724 & -14.6986 & -0.2128 & 0.3692 & -0.7948 \\
\hline & & 0.0416 & -19.4500 & 19.5333 & 0.0427 & -4.7790 & 4.8645 & 0.0431 & -0.1491 & 0.2353 \\
\hline & FEM [34] & -0.2148 & 57.9332 & -58.3627 & -0.2148 & 14.3377 & -14.7673 & -0.2147 & 0.3667 & -0.7962 \\
\hline & & 0.0431 & -19.1536 & 19.2399 & 0.0431 & -4.7614 & 4.8477 & 0.0431 & -0.1489 & 0.2352 \\
\hline & Present & -0.2127 & 58.3656 & -58.7911 & -0.2126 & 14.3408 & -14.7661 & -0.2126 & 0.3684 & -0.7936 \\
\hline & & 0.0420 & -19.1476 & 19.2315 & 0.0428 & -4.7524 & 4.8379 & 0.0430 & -0.1488 & 0.2348 \\
\hline
\end{tabular}

(i) $w^{*}=w^{*}(a / 2, b / 2,0), u^{*}=u^{*}(0, b / 2, \mp h / 2),\left(\sigma_{x}^{*}, \sigma_{y}^{*}\right)=\left(\sigma_{x}^{*}, \sigma_{y}^{*}\right)(a / 2, b / 2, \mp h / 2)$, and $\sigma_{x y}^{*}=\sigma_{x y}^{*}(0,0, \mp h / 2)$.

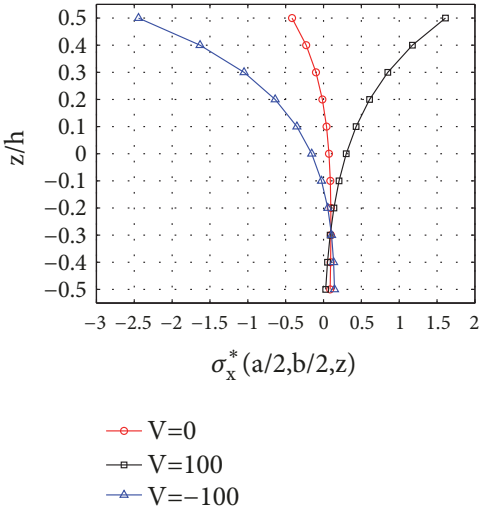

(a)

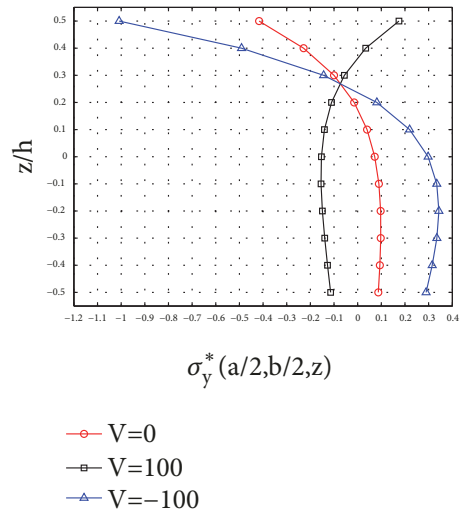

(b)

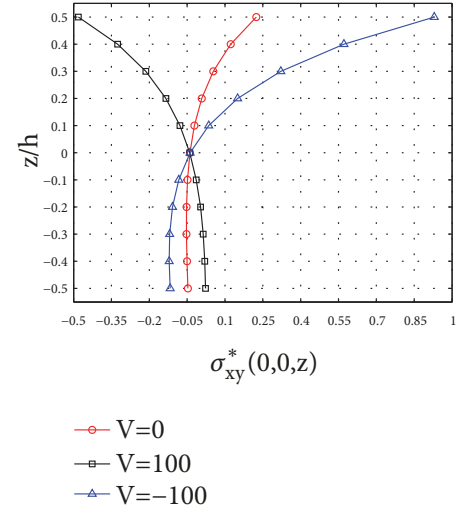

(c)

FIGURE 3: The variation of in-plane stress results through the thickness of the FG plate $\left(E_{t} / E_{b}=10, s=100\right)$ attached with the PFRC layer on the top surface with or without applied voltage. (a) The in-plane normal stress $\sigma_{x}^{*}$. (b) The in-plane normal stress $\sigma_{y}^{*}$. (c) The in-plane shear stress $\sigma_{x y}^{*}$. 
TAble 3: Results of the FG plate $\left(E_{t} / E_{b}=10\right)$ attached to the PFRC layer on the bottom surface with and without applied voltage.

\begin{tabular}{|c|c|c|c|c|c|c|c|c|c|c|}
\hline \multicolumn{2}{|c|}{ Aspect ratio } & \multicolumn{3}{|c|}{$s=10$} & \multicolumn{3}{|c|}{$\mathrm{s}=20$} & \multicolumn{3}{|c|}{$s=100$} \\
\hline Quantity & Theory & $\mathrm{V}=0$ & $V=100$ & $V=-100$ & $\mathrm{~V}=0$ & $V=100$ & $\mathrm{~V}=-100$ & $\mathrm{~V}=0$ & $\mathrm{~V}=100$ & $V=-100$ \\
\hline \multirow[t]{4}{*}{$w^{*}$} & HOSNT [35] & -0.9472 & 359.1410 & -361.0400 & -0.9172 & 89.2463 & -91.0807 & -0.9067 & 2.7015 & -4.1494 \\
\hline & $3 \mathrm{D}[33]$ & -0.9428 & 359.0874 & -360.9938 & -0.9164 & 89.5468 & -91.3877 & -0.9076 & 2.7147 & -4.5346 \\
\hline & FEM [34] & -0.9416 & 360.3108 & -362.1940 & -0.9205 & 89.4064 & -91.2392 & -0.9100 & 2.7028 & -4.5180 \\
\hline & Present & -0.9486 & 363.9614 & -365.8587 & -0.9192 & 89.8131 & -91.6515 & -0.9098 & 2.7131 & -4.5327 \\
\hline \multirow[t]{8}{*}{$u^{*}$} & HOSNT [35] & -0.0191 & 12.6577 & -12.6960 & -0.0192 & 2.9598 & -2.9982 & -0.0192 & 0.0975 & -0.1359 \\
\hline & & 0.0093 & 0.2688 & -0.2502 & 0.0093 & 0.0861 & -0.0675 & 0.0093 & 0.0125 & 0.0060 \\
\hline & $3 \mathrm{D}[33]$ & -0.0192 & 12.4664 & -12.5049 & -0.0193 & 2.9557 & -2.9942 & -0.0193 & 0.0978 & -0.1364 \\
\hline & & 0.0093 & 0.2578 & -0.2391 & 0.0093 & 0.0835 & -0.0649 & 0.0093 & 0.0124 & 0.0062 \\
\hline & FEM [34] & -0.0193 & 11.9237 & -11.9622 & -0.0193 & 2.9147 & -2.9532 & -0.0192 & 0.0974 & -0.1359 \\
\hline & & 0.0093 & 0.1967 & -0.1781 & 0.0093 & 0.0811 & -0.0625 & 0.0093 & 0.0125 & 0.0061 \\
\hline & Present & -0.0193 & 11.9869 & -12.0256 & -0.0193 & 2.9241 & -2.9627 & -0.0193 & 0.0977 & -0.1363 \\
\hline & & 0.0093 & 0.1609 & -0.1424 & 0.0093 & 0.0775 & -0.0589 & 0.0093 & 0.0124 & 0.0062 \\
\hline \multirow[t]{8}{*}{$\sigma_{x}^{*}$} & HOSNT [35] & 0.0874 & -50.2609 & 50.4364 & 0.0877 & -11.8397 & 12.0150 & 0.0876 & -0.3808 & 0.5561 \\
\hline & & -0.4202 & 47.7941 & -48.6351 & -0.4147 & 11.1666 & -11.9961 & -0.4129 & 0.0441 & -0.5698 \\
\hline & $3 \mathrm{D}[33]$ & 0.0865 & -48.6233 & 48.7963 & 0.0866 & -11.6559 & 11.8291 & 0.0866 & -0.3775 & 0.5507 \\
\hline & & -0.4228 & 47.6247 & -48.4703 & -0.4179 & 11.4491 & -12.2848 & -0.4163 & 0.0564 & -0.8890 \\
\hline & FEM [34] & 0.0883 & -47.8463 & 48.0230 & 0.0883 & -11.7681 & 11.9448 & 0.0883 & -0.3842 & 0.5608 \\
\hline & & -0.4250 & 50.8126 & -51.6626 & -0.4250 & 11.7704 & -12.6204 & -0.4246 & 0.0546 & -0.9039 \\
\hline & Present & 0.0872 & -47.1332 & 47.3076 & 0.0867 & -11.5509 & 11.7243 & 0.0865 & -0.3768 & 0.5499 \\
\hline & & -0.4252 & 52.1247 & -52.9752 & -0.4183 & 11.7060 & -12.5427 & -0.4161 & 0.0558 & -0.8880 \\
\hline \multirow[t]{8}{*}{$\overline{\sigma_{y}^{*}}$} & HOSNT [35] & 0.0877 & -32.4460 & 32.6220 & 0.0879 & -8.0425 & 8.2183 & 0.0878 & -0.2373 & 0.4130 \\
\hline & & -0.4175 & 186.4510 & -187.2890 & -0.4130 & 46.6489 & -47.4769 & -0.4111 & 1.4757 & -2.2979 \\
\hline & $3 \mathrm{D}[33]$ & 0.0867 & -31.3030 & 31.4763 & 0.0868 & -7.8872 & 8.0607 & 0.0868 & -0.2338 & 0.4074 \\
\hline & & -0.4212 & 185.7531 & -186.5955 & -0.4162 & 46.9151 & -47.7476 & -0.4146 & 1.4889 & -2.3181 \\
\hline & FEM [34] & 0.0885 & -31.8707 & 32.0478 & 0.0885 & -8.0314 & 8.2085 & 0.0885 & -0.2378 & 0.4147 \\
\hline & & -0.4233 & 190.3620 & -191.2086 & -0.4232 & 47.8967 & -48.7431 & -0.4229 & 1.5168 & -2.3626 \\
\hline & Present & 0.0874 & -31.4381 & 31.6129 & 0.0869 & -7.8865 & 8.0602 & 0.0867 & -0.2334 & 0.4068 \\
\hline & & -0.4236 & 188.7205 & -189.5677 & -0.4166 & 47.0638 & -47.8971 & -0.4144 & 1.4874 & -2.3162 \\
\hline \multirow[t]{8}{*}{$\overline{\sigma_{x y}^{*}}$} & HOSNT [35] & -0.0462 & 21.2813 & 21.7741 & -0.0465 & 5.2540 & -5.3470 & -0.0465 & 0.1638 & -0.2568 \\
\hline & & 0.2239 & -62.8314 & 63.2801 & 0.2234 & -15.6605 & 16.1073 & 0.2231 & -0.4137 & 0.8600 \\
\hline & $3 \mathrm{D}[33]$ & -0.0466 & 21.4662 & -21.5594 & -0.0467 & 5.2583 & -5.3516 & -0.0467 & 0.1646 & -0.2579 \\
\hline & & 0.2249 & -62.8348 & 63.2847 & 0.2240 & -15.7140 & 16.1620 & 0.2237 & -0.4161 & 0.8634 \\
\hline & FEM [34] & -0.0476 & 21.4743 & -21.5695 & -0.0476 & 5.3330 & -5.4282 & -0.0476 & 0.1674 & -0.2626 \\
\hline & & 0.2282 & -64.9662 & 65.4226 & 0.2282 & -16.0699 & 16.5264 & 0.2282 & -0.4228 & 0.8791 \\
\hline & Present & -0.0468 & 21.1201 & -21.2138 & -0.0467 & 5.2341 & -5.3275 & -0.0467 & 0.1644 & -0.2578 \\
\hline & & 0.2232 & -64.4092 & 64.8557 & 0.2236 & -15.8057 & 16.2528 & 0.2237 & -0.4159 & 0.8632 \\
\hline
\end{tabular}

(i) $w^{*}=w^{*}(a / 2, b / 2,0), u^{*}=u^{*}(0, b / 2, \mp h / 2),\left(\sigma_{x}^{*}, \sigma_{y}^{*}\right)=\left(\sigma_{x}^{*}, \sigma_{y}^{*}\right)(a / 2, b / 2, \mp h / 2)$, and $\sigma_{x y}^{*}=\sigma_{x y}^{*}(0,0, \mp h / 2)$.

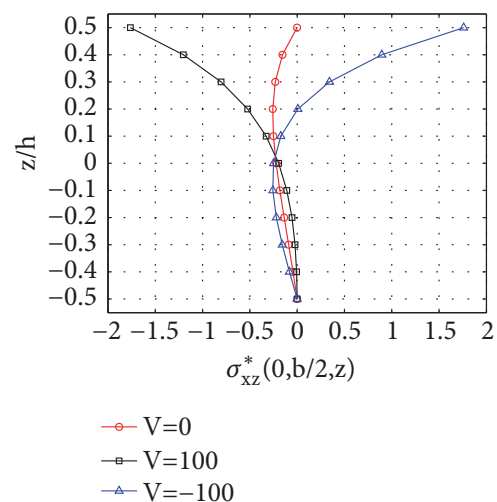

(a)

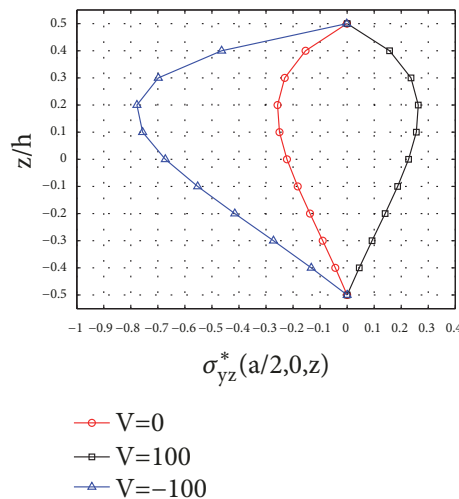

(b)

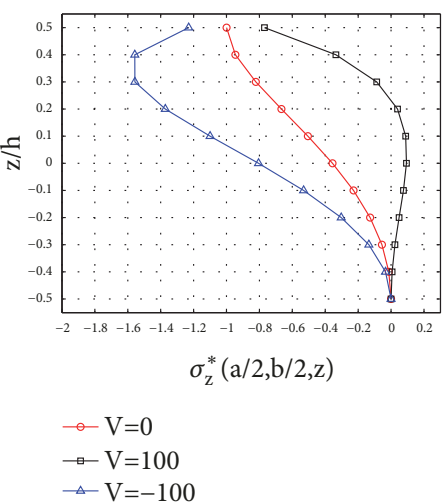

(c)

FIGURE 4: The variation of transverse stress results through the thickness of the FG plate $\left(E_{t} / E_{b}=10, s=100\right)$ attached with the PFRC layer on the top surface with or without applied voltage. (a) The transverse shear stress $\sigma_{x z}^{*}$. (b) The transverse shear stress $\sigma_{y z}^{*}$. (c) The transverse normal stress $\sigma_{z}^{*}$. 
TABLe 4: Results of the FG plate $\left(E_{t} / E_{b}=0.1\right)$ attached to the PFRC layer on the bottom surface with and without applied voltage.

\begin{tabular}{|c|c|c|c|c|c|c|c|c|c|c|}
\hline \multicolumn{2}{|c|}{ Aspect ratio } & \multicolumn{3}{|c|}{$\mathrm{s}=10$} & \multicolumn{3}{|c|}{$s=20$} & \multicolumn{3}{|c|}{$\mathrm{s}=100$} \\
\hline Quantity & Theory & $\mathrm{V}=0$ & $\mathrm{~V}=100$ & $V=-100$ & $\mathrm{~V}=0$ & $\mathrm{~V}=100$ & $V=-100$ & $\mathrm{~V}=0$ & $\mathrm{~V}=100$ & $\mathrm{~V}=-100$ \\
\hline \multirow[t]{4}{*}{$w^{*}$} & HOSNT [35] & -9.1979 & 1776.2 & -1794.6 & -8.9792 & 430.7050 & -448.6630 & -8.9093 & 8.5929 & -26.4115 \\
\hline & 3D [33] & -9.2748 & 1748.2 & -1807.5 & -9.0549 & 436.0142 & -454.1240 & -8.9338 & 8.7587 & -26.7281 \\
\hline & FEM [34] & -9.2761 & 1789.0 & -1766.7 & -9.0233 & 430.4678 & -448.5145 & -8.9364 & 8.6323 & -26.5051 \\
\hline & Present & -9.2090 & 1794.1 & -1812.5 & -9.0354 & 435.9295 & -454.0002 & -8.9801 & 8.7430 & -26.7031 \\
\hline \multirow[t]{8}{*}{$u^{*}$} & HOSNT [35] & -0.0877 & 57.1545 & -57.3300 & -0.0874 & 14.0393 & -14.2140 & -0.0872 & 0.4755 & -0.6500 \\
\hline & & 0.1878 & 0.7828 & -0.4073 & 0.1913 & 0.4707 & -0.0880 & 0.1925 & 0.2053 & 0.1797 \\
\hline & $3 \mathrm{D}[33]$ & -0.0890 & 57.1020 & -57.2801 & -0.0886 & 14.1124 & -14.2896 & -0.0885 & 0.4783 & -0.6552 \\
\hline & & 0.1890 & 0.5288 & -0.1507 & 0.1925 & 0.3882 & -0.0032 & 0.1936 & 0.2029 & 0.1844 \\
\hline & FEM [34] & -0.0877 & 57.1020 & -57.0792 & -0.0878 & 14.0431 & -14.2186 & -0.0877 & 0.4760 & -0.6514 \\
\hline & & 0.1931 & -0.0201 & 0.4063 & 0.1932 & 0.3963 & -0.0100 & 0.1930 & 0.2046 & 0.1815 \\
\hline & Present & -0.0883 & 57.3954 & -57.5720 & -0.0884 & 14.1204 & -14.2972 & -0.0884 & 0.4779 & -0.6546 \\
\hline & & 0.1890 & -0.3857 & 0.7637 & 0.1925 & 0.3335 & 0.0515 & 0.1936 & 0.2030 & 0.1843 \\
\hline \multirow[t]{8}{*}{$\sigma_{x}^{*}$} & HOSNT [35] & 0.4122 & -200.2660 & 201.0910 & 0.4101 & -49.1317 & 49.9519 & 0.4094 & -1.5643 & 2.3830 \\
\hline & & -0.0870 & 5.1151 & -5.2891 & -0.0853 & 1.1740 & -1.3446 & -0.0848 & -0.0349 & -0.1347 \\
\hline & 3D [33] & 0.4023 & -195.9356 & 196.7419 & 0.4011 & -48.4127 & 49.2150 & 0.4005 & -1.5486 & 2.3495 \\
\hline & & -0.0882 & 5.4977 & -5.6753 & -0.0871 & 1.2984 & -1.4726 & -0.0866 & -0.0313 & -0.1419 \\
\hline & FEM [34] & 0.4060 & -198.9894 & 199.8015 & 0.4061 & -49.1587 & 49.9708 & 0.4058 & -1.5729 & 2.3844 \\
\hline & & -0.0882 & 5.7883 & -5.9647 & -0.0882 & 1.3181 & -1.4945 & -0.0881 & -0.0328 & -0.1435 \\
\hline & Present & 0.4072 & -197.2765 & 198.0908 & 0.4012 & -48.3838 & 49.1861 & 0.3992 & -1.5440 & 2.3424 \\
\hline & & -0.0883 & 5.8572 & -6.0338 & -0.0869 & 1.3117 & -1.4856 & -0.0865 & -0.0317 & -0.1413 \\
\hline \multirow[t]{8}{*}{$\sigma_{y}^{*}$} & HOSNT [35] & 0.4209 & -58.3826 & 59.2244 & 0.4185 & -14.2690 & 15.1060 & 0.4177 & -0.1697 & 1.0052 \\
\hline & & -0.0862 & 18.5407 & -18.7130 & -0.0845 & 4.6123 & -4.7813 & -0.0840 & 0.1044 & -0.2724 \\
\hline & $3 \mathrm{D}[33]$ & 0.4115 & -54.9286 & 55.7515 & 0.4093 & -13.5769 & 14.3954 & 0.4085 & -0.1529 & 0.9700 \\
\hline & & -0.0880 & 18.8895 & -19.0655 & -0.0863 & 4.7369 & -4.9096 & -0.0858 & 0.1082 & -0.2798 \\
\hline & FEM [34] & 0.4148 & -54.2976 & 55.1272 & 0.4147 & -13.5690 & 14.3984 & 0.4143 & -0.1484 & 0.9771 \\
\hline & & -0.0874 & 19.2664 & -19.4412 & -0.0874 & 4.8161 & -4.9909 & -0.0873 & 0.1096 & -0.2842 \\
\hline & Present & 0.4156 & -55.5255 & 56.3568 & 0.4094 & -13.5211 & 14.3400 & 0.4075 & -0.1491 & 0.9640 \\
\hline & & -0.0875 & 19.1071 & -19.2822 & -0.0861 & 4.7396 & -4.9118 & -0.0857 & 0.1077 & -0.2791 \\
\hline \multirow[t]{8}{*}{$\sigma_{x y}^{*}$} & HOSNT [35] & -0.2164 & 67.1785 & -67.6112 & -0.2153 & 16.4960 & -16.9266 & -0.2150 & 0.4517 & -0.8817 \\
\hline & & 0.0450 & -6.5236 & 6.6136 & 0.0458 & -1.6054 & 1.6971 & 0.0461 & -0.0201 & 0.1123 \\
\hline & $3 \mathrm{D}$ [33] & -0.2193 & 67.4898 & -67.9285 & -0.2182 & 16.6863 & -17.1227 & -0.2178 & 0.4581 & -0.8937 \\
\hline & & 0.0453 & -6.5681 & 6.6587 & 0.0461 & -1.6255 & 1.7177 & 0.0464 & -0.0207 & 0.1135 \\
\hline & FEM [34] & -0.2208 & 68.2317 & -68.6734 & -0.2209 & 16.8966 & -17.3383 & -0.2208 & 0.4635 & -0.9051 \\
\hline & & 0.0472 & -6.7491 & 6.8436 & 0.0472 & -1.6521 & 1.7466 & 0.0472 & -0.0207 & 0.1151 \\
\hline & Present & -0.2177 & 67.8268 & -68.2621 & -0.2177 & 16.6922 & -17.1276 & -0.2177 & 0.4574 & -0.8928 \\
\hline & & 0.0453 & -6.7182 & 6.8087 & 0.0461 & -1.6333 & 1.7256 & 0.0464 & -0.0207 & 0.1134 \\
\hline
\end{tabular}

(i) $w^{*}=w^{*}(a / 2, b / 2,0), u^{*}=u^{*}(0, b / 2, \mp h / 2),\left(\sigma_{x}^{*}, \sigma_{y}^{*}\right)=\left(\sigma_{x}^{*}, \sigma_{y}^{*}\right)(a / 2, b / 2, \mp h / 2)$, and $\sigma_{x y}^{*}=\sigma_{x y}^{*}(0,0, \mp h / 2)$.

TABLE 5: The transverse stress results of the FG plate $\left(E_{t} / E_{b}=10\right)$ attached to the PFRC layer on the top surface with and without applied voltage.

\begin{tabular}{|c|c|c|c|c|c|c|c|c|c|c|}
\hline \multicolumn{2}{|c|}{ Aspect ratio } & \multicolumn{3}{|c|}{$\mathrm{s}=10$} & \multicolumn{3}{|c|}{$\mathrm{s}=20$} & \multicolumn{3}{|c|}{$s=100$} \\
\hline Quantity & Theory & $\mathrm{V}=0$ & $\mathrm{~V}=100$ & $\mathrm{~V}=-100$ & $\mathrm{~V}=0$ & $\mathrm{~V}=100$ & $V=-100$ & $\mathrm{~V}=0$ & $\mathrm{~V}=100$ & $V=-100$ \\
\hline \multirow{2}{*}{$\sigma_{x z}^{*}$} & $3 \mathrm{D}[33]$ & -0.2218 & 2.7211 & -3.1646 & -0.2225 & 0.4628 & -0.9079 & -0.2228 & -0.1960 & -0.2495 \\
\hline & Present & -0.2218 & 2.6559 & -3.1001 & -0.2226 & 0.4572 & -0.9024 & -0.2228 & -0.1961 & -0.2495 \\
\hline \multirow{2}{*}{$\sigma_{y z}^{*}$} & $3 \mathrm{D}[33]$ & -0.2215 & 43.9606 & -44.4035 & -0.2223 & 10.9839 & -11.4284 & -0.2225 & 0.2278 & -0.6729 \\
\hline & Present & -0.2221 & 44.1326 & -44.5763 & -0.2224 & 10.9897 & -11.4345 & -0.2225 & 0.2276 & -0.6726 \\
\hline \multirow[t]{2}{*}{$\sigma_{z}^{*}$} & $3 \mathrm{D}[33]$ & -0.3537 & 43.9487 & -44.6562 & -0.3554 & 10.8462 & -11.5570 & -0.3559 & 0.0938 & -0.8056 \\
\hline & Present & -0.3552 & 44.3729 & -45.0834 & -0.3557 & 10.8666 & -11.5781 & -0.3559 & 0.0935 & -0.8053 \\
\hline
\end{tabular}

(i) $\sigma_{x z}^{*}=\sigma_{x z}^{*}(0, b / 2, h / 2), \sigma_{y z}^{*}=\sigma_{y z}^{*}(a / 2,0, h / 2)$, and $\sigma_{z}^{*}=\sigma_{z}^{*}(a / 2, b / 2, h / 2)$. 
TABLE 6: The transverse stress results of the FG plate $\left(E_{t} / E_{b}=0.1\right)$ attached to the PFRC layer on the top surface with and without applied voltage.

\begin{tabular}{|c|c|c|c|c|c|c|c|c|c|c|}
\hline \multicolumn{2}{|c|}{ Aspect ratio } & \multicolumn{3}{|c|}{$s=10$} & \multicolumn{3}{|c|}{$\mathrm{s}=20$} & \multicolumn{3}{|c|}{$s=100$} \\
\hline Quantity & Theory & $\mathrm{V}=0$ & $V=100$ & $V=-100$ & $\mathrm{~V}=0$ & $\mathrm{~V}=100$ & $\mathrm{~V}=-100$ & $\mathrm{~V}=0$ & $\mathrm{~V}=100$ & $V=-100$ \\
\hline \multirow{2}{*}{$\sigma_{x z}^{*}$} & $3 \mathrm{D}[33]$ & -0.2248 & -41.5579 & 41.1083 & -0.2255 & -10.8859 & 10.4348 & -0.2258 & -0.6565 & 0.2049 \\
\hline & Present & -0.2248 & -42.3466 & 41.8971 & -0.2254 & -10.9476 & 10.4967 & -0.2256 & -0.6570 & 0.2057 \\
\hline \multirow[t]{2}{*}{$\overline{\sigma_{y z}^{*}}$} & $3 \mathrm{D}[33]$ & -0.2114 & 79.9749 & -80.3977 & -0.2117 & 20.2434 & -20.6668 & -0.2118 & 0.6118 & -1.0353 \\
\hline & Present & -0.2110 & 80.4406 & -80.8627 & -0.2113 & 20.2345 & -20.6571 & -0.2114 & 0.6101 & -1.0329 \\
\hline \multirow[t]{2}{*}{$\overline{\sigma_{z}^{*}}$} & $3 \mathrm{D}[33]$ & -0.6177 & 115.6052 & -116.8407 & -0.6184 & 28.8665 & -30.1034 & -0.6186 & 0.5663 & -1.8036 \\
\hline & Present & -0.6177 & 117.0028 & -118.2382 & -0.6173 & 28.8020 & -30.0366 & -0.6171 & 0.5598 & -1.7941 \\
\hline
\end{tabular}

(i) $\sigma_{x z}^{*}=\sigma_{x z}^{*}(0, b / 2, h / 2), \sigma_{y z}^{*}=\sigma_{y z}^{*}(a / 2,0, h / 2)$, and $\sigma_{z}^{*}=\sigma_{z}^{*}(a / 2, b / 2, h / 2)$.

of the FG plate. The present higher-order theory considers hyperbolic in-plane displacement field and parabolic transverse displacement field. The electrical potential in the PFRC layer is modeled as linear distribution. The governing equations are derived by the principle of the minimum potential energy and Navier's procedure is applied to solve the equations. The static analysis of the smart FG plate subjected electromechanical load is developed to illustrate the efficiency of the proposed method. The variation of displacement and stress is significantly influenced by the sign of applied voltage on the PFRC layer. In the numerical results, the good agreement was found between the present results and 3D exact solutions for different aspect ratios, applied voltages, and functionally graded material parameters. The present theory is very accurate and efficient in predicting the bending deformations of smart FG plates.

\section{Appendix}

A.

$$
\begin{aligned}
N_{x}= & A_{11} \frac{\partial u_{0}}{\partial x}+A_{12} \frac{\partial v_{0}}{\partial y}+B_{11} \frac{\partial u_{1}}{\partial x}+B_{12} \frac{\partial v_{1}}{\partial y} \\
& +A_{13} w_{1}+A_{11}^{s} \frac{\partial u_{2}}{\partial x}+A_{12}^{s} \frac{\partial v_{2}}{\partial y}+2 B_{13} w_{2} \\
& +(-1)^{l} e_{31} \frac{\partial \phi_{0}}{\partial x}, \\
N_{y}= & A_{12} \frac{\partial u_{0}}{\partial x}+A_{22} \frac{\partial v_{0}}{\partial y}+B_{12} \frac{\partial u_{1}}{\partial x}+B_{22} \frac{\partial v_{1}}{\partial y} \\
& +A_{23} w_{1}+A_{12}^{s} \frac{\partial u_{2}}{\partial x}+A_{22}^{s} \frac{\partial v_{2}}{\partial y}+2 B_{23} w_{2} \\
N_{x y}= & A_{66}\left(\frac{\partial u_{0}}{\partial y}+\frac{\partial v_{0}}{\partial x}\right)+B_{66}\left(\frac{\partial u_{1}}{\partial y}+\frac{\partial v_{1}}{\partial x}\right) \\
& +A_{66}^{s}\left(\frac{\partial u_{2}}{\partial y}+\frac{\partial v_{2}}{\partial x}\right), \\
M_{x}= & B_{11} \frac{\partial u_{0}}{\partial x}+B_{12} \frac{\partial v_{0}}{\partial y}+D_{11} \frac{\partial u_{1}}{\partial x}+D_{12} \frac{\partial v_{1}}{\partial y} \\
& +B_{13} w_{1}+B_{11}^{s} \frac{\partial u_{2}}{\partial x}+B_{12}^{s} \frac{\partial v_{2}}{\partial y}+2 D_{13} w_{2} \\
& +\frac{e_{31}}{h_{p}} \frac{\partial \phi_{0}}{\partial x} \int_{t_{1}}^{t_{2}} z d z
\end{aligned}
$$

$$
\begin{aligned}
M_{y}= & B_{12} \frac{\partial u_{0}}{\partial x}+B_{22} \frac{\partial v_{0}}{\partial y}+D_{12} \frac{\partial u_{1}}{\partial x}+D_{22} \frac{\partial v_{1}}{\partial y} \\
& +B_{23} w_{1}+B_{12}^{s} \frac{\partial u_{2}}{\partial x}+B_{22}^{s} \frac{\partial v_{2}}{\partial y}+2 D_{23} w_{2} \\
M_{x y}= & B_{66}\left(\frac{\partial u_{0}}{\partial y}+\frac{\partial v_{0}}{\partial x}\right)+D_{66}\left(\frac{\partial u_{1}}{\partial y}+\frac{\partial v_{1}}{\partial x}\right) \\
& +B_{66}^{s}\left(\frac{\partial u_{2}}{\partial y}+\frac{\partial v_{2}}{\partial x}\right), \\
P_{x}= & A_{11}^{s} \frac{\partial u_{0}}{\partial x}+A_{12}^{s} \frac{\partial v_{0}}{\partial y}+B_{11}^{s} \frac{\partial u_{1}}{\partial x}+B_{12}^{s} \frac{\partial v_{1}}{\partial y} \\
& +A_{13}^{s} w_{1}+D_{11}^{s} \frac{\partial u_{2}}{\partial x}+D_{12}^{s} \frac{\partial v_{2}}{\partial y}+2 B_{13}^{s} w_{2} \\
& +\frac{e_{31}}{h_{p}} \frac{\partial \phi_{0}}{\partial x} \int_{t_{1}}^{t_{2}} f d z, \\
P_{y}= & A_{12}^{s} \frac{\partial u_{0}}{\partial x}+A_{22}^{s} \frac{\partial v_{0}}{\partial y}+B_{12}^{s} \frac{\partial u_{1}}{\partial x}+B_{22}^{s} \frac{\partial v_{1}}{\partial y} \\
& +A_{23}^{s} w_{1}+D_{12}^{s} \frac{\partial u_{2}}{\partial x}+D_{22}^{s} \frac{\partial v_{2}}{\partial y}+2 B_{23}^{s} w_{2} \\
& +B_{33} w_{1}+B_{13}^{s} \frac{\partial u_{2}}{\partial x}+B_{23}^{s} \frac{\partial v_{2}}{\partial y}+2 D_{33} w_{2} \\
M_{z}= & B_{13} \frac{\partial u_{0}}{\partial x}+B_{23} \frac{\partial v_{0}}{\partial y}+D_{13} \frac{\partial u_{1}}{\partial x}+D_{23} \frac{\partial v_{1}}{\partial y} \\
P_{x y}= & A_{66}^{s}\left(\frac{\partial u_{0}}{\partial y}+\frac{\partial v_{0}}{\partial x}\right)+B_{66}^{s}\left(\frac{\partial u_{1}}{\partial y}+\frac{\partial v_{1}}{\partial x}\right) \\
& +D_{66}^{s}\left(\frac{\partial u_{2}}{\partial y}+\frac{\partial w_{2}}{\partial x}\right) \\
M_{x z}= & B_{55} \frac{\partial w_{0}}{\partial x}+B_{55} u_{1}+D_{55} \frac{\partial w_{1}}{\partial x}+Y_{55} u_{2} \\
&
\end{aligned}
$$




$$
\begin{aligned}
& P_{x z}= X_{55} \frac{\partial w_{0}}{\partial x}+X_{55} u_{1}+Y_{55} \frac{\partial w_{1}}{\partial x}+X_{55}^{s} u_{2} \\
&+Z_{55} \frac{\partial w_{2}}{\partial x} \\
& P_{y z}= X_{44} \frac{\partial w_{0}}{\partial y}+X_{44} v_{1}+Y_{44} \frac{\partial w_{1}}{\partial y}+X_{44}^{s} v_{2} \\
&+Z_{44} \frac{\partial w_{2}}{\partial y}, \\
& Q_{x z}= A_{55} \frac{\partial w_{0}}{\partial x}+A_{55} u_{1}+B_{55} \frac{\partial w_{1}}{\partial x}+X_{55} u_{2} \\
&+D_{55} \frac{\partial w_{2}}{\partial x}, \\
&+H_{44} \frac{\partial w_{2}}{\partial y}, \\
& R_{y z}= A_{44} \frac{\partial w_{0}}{\partial y}+A_{44} v_{1}+B_{44} \frac{\partial w_{1}}{\partial y}+X_{44} v_{2} \\
&+Y_{44} \frac{\partial w_{2}}{\partial y}, \\
&+A_{33} \frac{\partial w_{1}}{\partial x}+A_{13}^{s} \frac{\partial u_{2}}{\partial x}+A_{23}^{s} \frac{\partial v_{2}}{\partial y}+2 B_{33} w_{2} \\
& Q_{z}= A_{13} \frac{\partial w_{0}}{\partial x}+A_{23} \frac{\partial v_{0}}{\partial y}+B_{13} \frac{\partial u_{1}}{\partial x}+B_{23} \frac{\partial v_{1}}{\partial y}+Z_{44} v_{2} \\
& R_{1}+F_{55} \frac{\partial w_{1}}{\partial x}+Z_{55} u_{2} \\
& \\
& R_{y z}
\end{aligned}
$$

B.

$$
\begin{aligned}
& k_{11}=\alpha^{2} A_{11}+\beta^{2} A_{66} \text {, } \\
& k_{12}=\alpha \beta\left(A_{12}+A_{66}\right) \text {, } \\
& k_{13}=0 \text {, } \\
& k_{14}=\alpha^{2} B_{11}+\beta^{2} B_{66} \text {, } \\
& k_{15}=\alpha \beta\left(B_{12}+B_{66}\right) \text {, } \\
& k_{16}=-\alpha A_{13} \text {, } \\
& k_{17}=\alpha^{2} A_{11}^{s}+\beta^{2} A_{66}^{s} \text {, } \\
& k_{18}=\alpha \beta\left(A_{12}^{s}+A_{66}^{s}\right) \text {, } \\
& k_{19}=-2 \alpha B_{13} \text {, } \\
& k_{22}=\alpha^{2} A_{66}+\beta^{2} A_{22} \text {, } \\
& k_{23}=0 \text {, } \\
& k_{24}=\alpha \beta\left(B_{12}+B_{66}\right) \text {, } \\
& k_{25}=\alpha^{2} B_{66}+\beta^{2} B_{22} \text {, } \\
& k_{26}=-\beta A_{23} \text {, } \\
& k_{27}=\alpha \beta\left(A_{12}^{s}+A_{66}^{s}\right) \\
& k_{28}=\alpha^{2} A_{66}^{s}+\beta^{2} A_{22}^{s} \text {, } \\
& k_{29}=-2 \beta B_{23} \text {, } \\
& k_{33}=\alpha^{2} A_{55}+\beta^{2} A_{44} \text {, } \\
& k_{34}=\alpha A_{55} \text {, } \\
& k_{35}=\beta A_{44} \text {, } \\
& k_{36}=\alpha^{2} B_{55}+\beta^{2} B_{44}, \\
& k_{37}=\alpha X_{55} \text {, } \\
& k_{38}=\beta X_{44} \text {, } \\
& k_{39}=\alpha^{2} D_{55}+\beta^{2} D_{44} \text {, } \\
& k_{44}=\alpha^{2} D_{11}+\beta^{2} D_{66}+A_{55} \text {, } \\
& k_{45}=\alpha \beta\left(D_{12}+D_{66}\right) \text {, } \\
& k_{46}=\alpha\left(B_{55}-B_{13}\right) \text {, } \\
& k_{47}=\alpha^{2} B_{11}^{s}+\beta^{2} B_{66}^{s}+X_{55}, \\
& k_{48}=\alpha \beta\left(B_{12}^{s}+B_{66}^{s}\right) \text {, } \\
& k_{49}=\alpha\left(D_{55}-2 D_{13}\right) \text {, } \\
& k_{55}=\alpha^{2} D_{66}+\beta^{2} D_{22}+A_{44} \text {, } \\
& k_{56}=\beta\left(B_{44}-B_{23}\right) \text {, }
\end{aligned}
$$

in which $l=1,2$ represent that the PFRC layer is either on the bottom or on the top, respectively.

$$
\begin{aligned}
& \left(A_{i j}, B_{i j}, D_{i j}, F_{i j}, H_{i j}, A_{i j}^{s}, B_{i j}^{s}, D_{i j}^{s}\right) \\
& \quad=\sum_{k=1}^{2} \int_{h_{k}}^{h_{k+1}}\left(1, z, z^{2}, z^{3}, f, z f, f^{2}\right) C_{i j}^{k} d z, \\
& \left(X_{i j}, Y_{i j}, Z_{i j}, X_{i j}^{s}\right)=\sum_{k=1}^{2} \int_{h_{k}}^{h_{k+1}}\left(1, z, z^{2}, f^{\prime}\right) f^{\prime} C_{i j}^{k} d z, \\
& t_{1}=\frac{(-1)^{l} h}{2}, \\
& t_{2}=(-1)^{l}\left(\frac{h}{2}+h_{p}\right), \\
& \quad l=1 \text { or } 2,
\end{aligned}
$$




$$
\begin{aligned}
& k_{57}=\alpha \beta\left(B_{12}^{s}+B_{66}^{s}\right), \\
& k_{58}=\alpha^{2} B_{66}^{s}+\beta^{2} B_{22}^{s}+X_{44}, \\
& k_{59}=\beta\left(D_{44}-2 D_{23}\right), \\
& k_{66}=\alpha^{2} D_{55}+\beta^{2} D_{44}+A_{33}, \\
& k_{67}=\alpha\left(Y_{55}-A_{13}^{s}\right), \\
& k_{68}=\beta\left(Y_{44}-A_{23}^{s}\right), \\
& k_{69}=\alpha^{2} F_{55}+\beta^{2} F_{44}+2 B_{33}, \\
& k_{77}=\alpha^{2} D_{11}^{s}+\beta^{2} D_{66}^{s}+X_{55}^{s}, \\
& k_{78}=\alpha \beta\left(D_{12}^{s}+D_{66}^{s}\right), \\
& k_{79}=\alpha\left(Z_{55}-2 B_{13}^{s}\right), \\
& k_{88}=\alpha^{2} D_{66}^{s}+\beta^{2} D_{22}^{s}+X_{44}^{s}, \\
& k_{89}=\beta\left(Z_{44}-2 B_{23}^{s}\right), \\
& k_{99}=\alpha^{2} H_{55}+\beta^{2} H_{44}+4 D_{33},
\end{aligned}
$$

and

$$
\begin{aligned}
& f_{1}=(-1)^{l} \alpha e_{31} \phi_{0 m n}, \\
& f_{2}=0, \\
& f_{3}=q_{m n}, \\
& f_{4}=\frac{\alpha e_{31} \phi_{0 m n}}{h_{p}} \int_{t_{1}}^{t_{2}} z d z, \\
& f_{5}=0, \\
& f_{6}=\left|t_{l}\right| q_{m n}, \\
& f_{7}=\frac{\alpha e_{31} \phi_{0 m n}}{h_{p}} \int_{t_{1}}^{t_{2}} f d z, \\
& f_{8}=0, \\
& f_{9}=t_{l}^{2} q_{m n} .
\end{aligned}
$$

\section{Data Availability}

The data used to support the findings of this study are available from the corresponding author upon request.

\section{Conflicts of Interest}

The authors declare that they have no conflicts of interest.

\section{Acknowledgments}

This work is supported by the National Natural Science Foundation of China (nos. 11572210 and 11172192).

\section{References}

[1] S. Hosseini-Hashemi, M. Fadaee, and S. R. Atashipour, "A new exact analytical approach for free vibration of Reissner-Mindlin functionally graded rectangular plates," International Journal of Mechanical Sciences, vol. 53, no. 1, pp. 11-22, 2011.

[2] T.-K. Nguyen, K. Sab, and G. Bonnet, "First-order shear deformation plate models for functionally graded materials," Composite Structures, vol. 83, no. 1, pp. 25-36, 2008.

[3] J. N. Reddy, "Analysis of functionally graded plates," International Journal for Numerical Methods in Engineering, vol. 47, no. 1-3, pp. 663-684, 2000.

[4] A. J. M. Ferreira, R. C. Batra, C. M. C. Roque, L. F. Qian, and P. A. L. S. Martins, "Static analysis of functionally graded plates using third-order shear deformation theory and a meshless method," Composite Structures, vol. 69, no. 4, pp. 449-457, 2005.

[5] A. J. M. Ferreira, R. C. Batra, C. M. C. Roque, L. F. Qian, and R. M. N. Jorge, "Natural frequencies of functionally graded plates by a meshless method," Composite Structures, vol. 75, no. 1-4, pp. 593-600, 2006.

[6] T. Kant and B. S. Manjunatha, "An unsymmetric FRC laminate $\mathrm{C}^{\circ}$ finite element model with 12 degrees of freedom per node," Engineering Computations, vol. 5, no. 4, pp. 300-308, 1988.

[7] R. P. Shimpi, H. Arya, and N. K. Naik, "A higher order displacement model for the plate analysis," Journal of Reinforced Plastics and Composites, vol. 22, no. 18, pp. 1667-1688, 2003.

[8] Y. M. Ghugal and A. S. Sayyad, "A static flexure of thick isotropic plates using trigonometric shear deformation theory," Journal of Solid Mechanics, vol. 2, no. 1, pp. 79-90, 2010.

[9] A. M. A. Neves, A. J. M. Ferreira, E. Carrera et al., "Bending of FGM plates by a sinusoidal plate formulation and collocation with radial basis functions," Mechanics Research Communications, vol. 38, no. 5, pp. 368-371, 2011.

[10] A. M. A. Neves, A. J. M. Ferreira, E. Carrera et al., "A quasi$3 \mathrm{D}$ hyperbolic shear deformation theory for the static and free vibration analysis of functionally graded plates," Composite Structures, vol. 94, no. 5, pp. 1814-1825, 2012.

[11] A. M. Zenkour, "Bending of FGM plates by a simplified fourunknown shear and normal deformations theory," International Journal of Applied Mechanics, vol. 5, no. 3, pp. 1-15, 2013.

[12] A. Bessaim, M. S. Houari, A. Tounsi, S. Mahmoud, and E. A. Bedia, "A new higher-order shear and normal deformation theory for the static and free vibration analysis of sandwich plates with functionally graded isotropic face sheets," Journal of Sandwich Structures \& Materials, vol. 15, no. 6, pp. 671-703, 2013.

[13] A. M. Zenkour, "A simple four-unknown refined theory for bending analysis of functionally graded plates," Applied Mathematical Modelling: Simulation and Computation for Engineering and Environmental Systems, vol. 37, no. 20-21, pp. 9041-9051, 2013.

[14] E. Carrera, S. Brischetto, M. Cinefra, and M. Soave, "Effects of thickness stretching in functionally graded plates and shells," Composites Part B: Engineering, vol. 42, no. 2, pp. 123-133, 2011.

[15] H. Hebali, A. Tounsi, M. S. A. Houari, A. Bessaim, and E. A. A. Bedia, "New quasi-3D hyperbolic shear deformation theory for the static and free vibration analysis of functionally graded plates," Journal of Engineering Mechanics, vol. 140, no. 2, pp. 374383, 2014.

[16] H.-T. Thai, T. P. Vo, T. Q. Bui, and T.-K. Nguyen, "A quasi-3D hyperbolic shear deformation theory for functionally graded plates," Acta Mechanica, vol. 225, no. 3, pp. 951-964, 2014. 
[17] Z. Belabed, M. S. A. Houari, A. Tounsi, S. R. Mahmoud, and O. Anwar Bég, "An efficient and simple higher order shear and normal deformation theory for functionally graded material (FGM) plates," Composites Part B: Engineering, vol. 60, pp. 274283, 2014

[18] A. S. Sayyad and Y. M. Ghugal, "On the free vibration analysis of laminated composite and sandwich plates: a review of recent literature with some numerical results," Composite Structures, vol. 129, pp. 177-201, 2015.

[19] Z. Q. Cheng and R. C. Batra, "Three-dimensional thermoelastic deformations of a functionally graded elliptic plate," Composites Part B: Engineering, vol. 31, no. 2, pp. 97-106, 2000.

[20] J. N. Reddy and Q. C. Zhen, “Three-dimensional thermomechanical deformations of functionally graded rectangular plates," European Journal of Mechanics - A/Solids, vol. 20, no. 5, pp. 841-855, 2001.

[21] S. S. Vel and R. C. Batra, "Three-dimensional analysis of transient thermal stresses in functionally graded plates," International Journal of Solids and Structures, vol. 40, no. 25, pp. 71817196, 2003.

[22] T. A. Anderson, "A 3-D elasticity solution for a sandwich composite with functionally graded core subjected to transverse loading by a rigid sphere," Composite Structures, vol. 60, no. 3, pp. 265-274, 2003.

[23] S. S. Vel and R. C. Batra, "Three-dimensional exact solution for the vibration of functionally graded rectangular plates," Journal of Sound and Vibration, vol. 272, no. 3-5, pp. 703-730, 2004.

[24] M. Kashtalyan, "Three-dimensional elasticity solution for bending of functionally graded rectangular plates," European Journal of Mechanics - A/Solids, vol. 23, no. 5, pp. 853-864, 2004.

[25] A. M. Zenkour, "Benchmark trigonometric and 3-D elasticity solutions for an exponentially graded thick rectangular plate," Archive of Applied Mechanics, vol. 77, no. 4, pp. 197-214, 2007.

[26] Y. Ootao and Y. Tanigawa, "Three-dimensional transient piezothermoelasticity in functionally graded rectangular plate bonded to a piezoelectric plate," International Journal of Solids and Structures, vol. 37, no. 32, pp. 4377-4401, 2000.

[27] J. N. Reddy and Z. Cheng, "Three-dimensional solutions of smart functionally graded plates," Journal of Applied Mechanics, vol. 68 , no. 2, pp. 234-241, 2001.

[28] X. Q. He, T. Y. Ng, S. Sivashanker, and K. M. Liew, "Active control of FGM plates with integrated piezoelectric sensors and actuators," International Journal of Solids and Structures, vol. 38, no. 9, pp. 1641-1655, 2001.

[29] X.-L. Huang and H.-S. Shen, "Vibration and dynamic response of functionally graded plates with piezoelectric actuators in thermal environments," Journal of Sound and Vibration, vol. 289, no. 1-2, pp. 25-53, 2006.

[30] M. H. Kargarnovin, M. M. Najafizadeh, and N. S. Viliani, "Vibration control of a functionally graded material plate patched with piezoelectric actuators and sensors under a constant electric charge," Smart Materials and Structures, vol. 16, no. 4, pp. 1252-1259, 2007.

[31] S. Brischetto and E. Carrera, "Refined 2D models for the analysis of functionally graded piezoelectric plates," Journal of Intelligent Material Systems and Structures, vol. 20, no. 15, pp. 1783-1797, 2009.

[32] N. Mallik and M. C. Ray, "Effective coefficients of piezoelectric fiber-reinforced composites," AIAA Journal, vol. 41, no. 4, pp. 704-710, 2003.
[33] M. C. Ray and H. M. Sachade, "Exact solutions for the functionally graded plates integrated with a layer of piezoelectric fiberreinforced composite," Journal of Applied Mechanics, vol. 73, no. 4, pp. 622-632, 2006.

[34] M. C. Ray and H. M. Sachade, "Finite element analysis of smart functionally graded plates," International Journal of Solids and Structures, vol. 43, no. 18-19, pp. 5468-5484, 2006.

[35] S. M. Shiyekar and T. Kant, "An electromechanical higher order model for piezoelectric functionally graded plates," International Journal of Mechanics and Materials in Design, vol. 6, no. 2, pp. 163-174, 2010.

[36] F. Delale and F. Erdogan, "The crack problem for a nonhomogeneous plane," Journal of Applied Mechanics, vol. 50, no. 3, pp. 609-614, 1983.

[37] A. M. A. Neves, A. J. M. Ferreira, E. Carrera et al., "A quasi3D sinusoidal shear deformation theory for the static and free vibration analysis of functionally graded plates," Composites Part B: Engineering, vol. 43, no. 2, pp. 711-725, 2012.

[38] A. M. A. Neves, A. J. M. Ferreira, E. Carrera et al., "Static, free vibration and buckling analysis of isotropic and sandwich functionally graded plates using a quasi-3D higher-order shear deformation theory and a meshless technique," Composites Part B: Engineering, vol. 44, no. 1, pp. 657-674, 2013.

[39] A. M. Neves, A. J. Ferreira, E. Carrera, M. Cinefra, R. M. Jorge, and C. M. Soares, "Buckling analysis of sandwich plates with functionally graded skins using a new quasi-3D hyperbolic sine shear deformation theory and collocation with radial basis functions," Journal of Applied Mathematics and Mechanics, vol. 92, no. 9, pp. 749-766, 2012. 


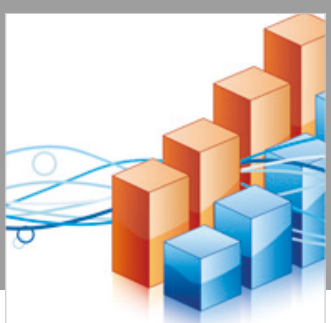

Advances in

Operations Research

\section{-n-m}
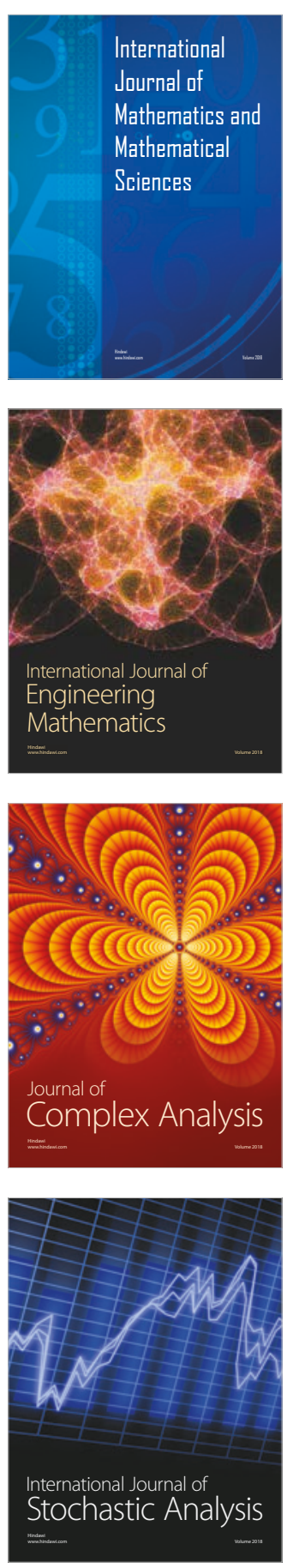
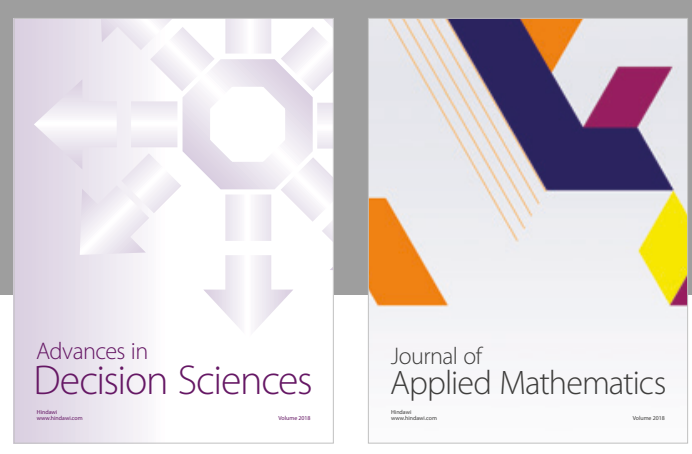

Journal of

Applied Mathematics
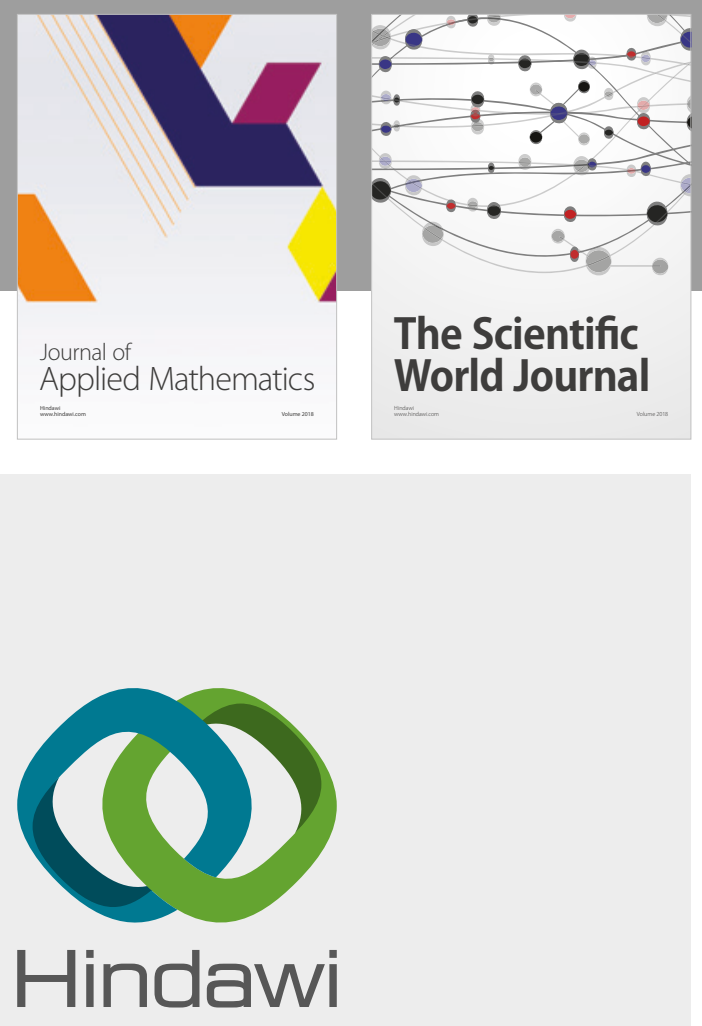

Submit your manuscripts at

www.hindawi.com

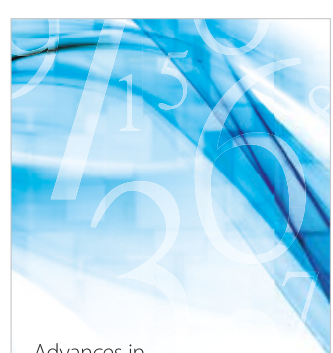

Advances in
Numerical Analysis
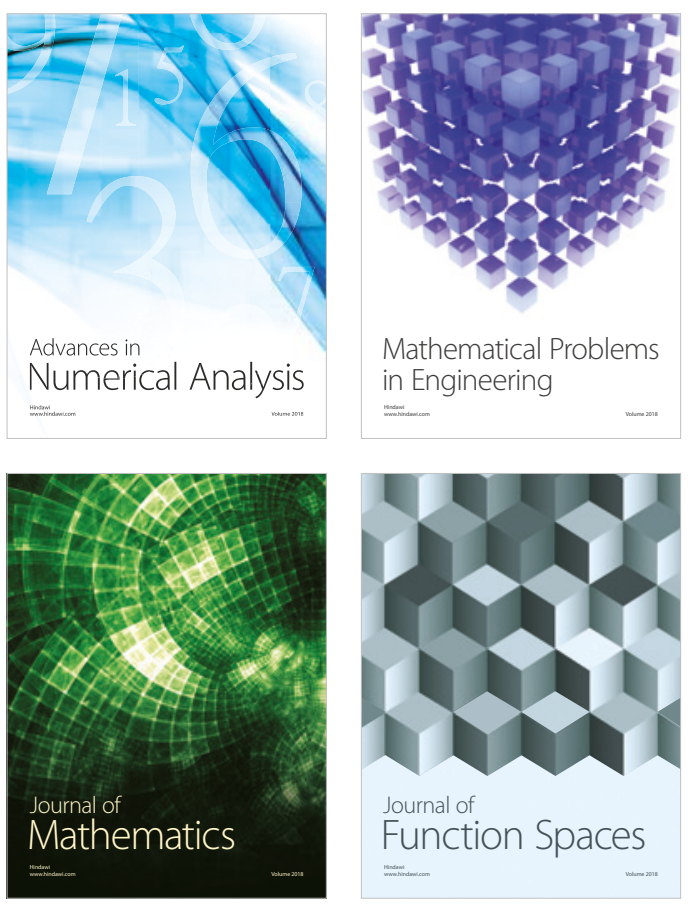

Mathematical Problems in Engineering

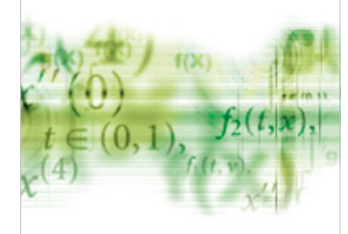

International Journal of

Differential Equations

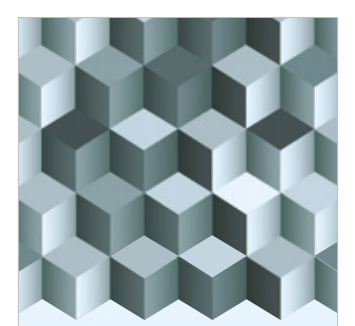

Journal of

Function Spaces

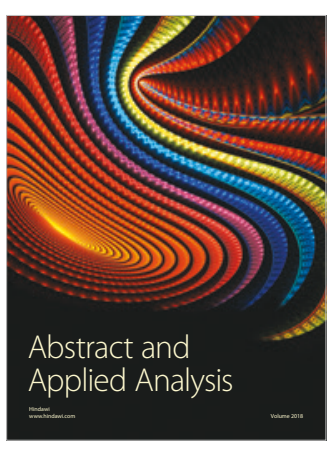

The Scientific

World Journal

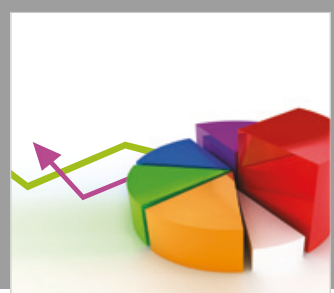

Journal of

Probability and Statistics
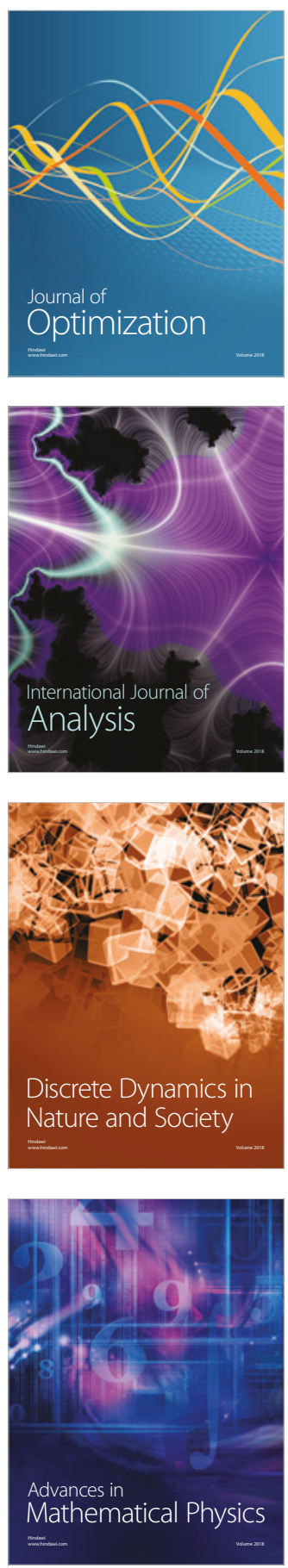